\title{
Conditional Knock-Out of Vesicular GABA Transporter Gene from Starburst Amacrine Cells Reveals the Contributions of Multiple Synaptic Mechanisms Underlying Direction Selectivity in the Retina
}

\author{
Zhe Pei, Qiang Chen, David Koren, Benno Giammarinaro, Hector Acaron Ledesma, and Wei Wei \\ Department of Neurobiology, The University of Chicago, Chicago, Illinois 60637
}

\begin{abstract}
Direction selectivity of direction-selective ganglion cells (DSGCs) in the retina results from patterned excitatory and inhibitory inputs onto DSGCs during motion stimuli. The inhibitory inputs onto DSGCs are directionally tuned to the antipreferred (null) direction and therefore potently suppress spiking during motion in the null direction. However, whether direction-selective inhibition is indispensable for direction selectivity is unclear. Here, we selectively eliminated the directional tuning of inhibitory inputs onto DSGCs by disrupting GABA release from the presynaptic interneuron starburst amacrine cell in the mouse retina. We found that, even without directionally tuned inhibition, direction selectivity can still be implemented in a subset of On-Off DSGCs by direction-selective excitation and a temporal offset between excitation and isotropic inhibition. Our results therefore demonstrate the concerted action of multiple synaptic mechanisms for robust direction selectivity in the retina.
\end{abstract}

Key words: direction selectivity; retina; starburst amacrine cell; synaptic excitation; synaptic inhibition; vesicular GABA transporter

Significance Statement

The direction-selective circuit in the retina has been a classic model to study neural computations by the brain. An important but unresolved question is how direction selectivity is implemented by directionally tuned excitatory and inhibitory mechanisms. Here we specifically removed the direction tuning of inhibition from the circuit. We found that direction tuning of inhibition is important but not indispensable for direction selectivity of DSGCs' spiking activity, and that the residual direction selectivity is implemented by direction-selective excitation and temporal offset between excitation and inhibition. Our results highlight the concerted actions of synaptic excitation and inhibition required for robust direction selectivity in the retina and provide critical insights into how patterned excitation and inhibition collectively implement sensory processing.

\section{Introduction}

In mammalian retina, the On-Off type of direction-selective ganglion cell (DSGC) encodes image motion in four cardinal directions (Barlow and Hill, 1963; Oyster and Barlow, 1967). Direction-selective spiking of these cells is generated by distinct patterns of synaptic inputs during preferred and null direction

Received March 10, 2015; revised Aug. 17, 2015; accepted Aug. 21, 2015.

Author contributions: W.W. designed research; Z.P., Q.C., D.K., B.G., H.A.L., and W.W. performed research; Z.P., Q.C., D.K., B.G., and W.W. analyzed data; Z.P., D.K., and W.W. wrote the paper.

This work was supported by the National Institutes of Health (Grant R01 EY024016), the E. Matilda Ziegler Foundation, Whitehall, Sloan Research, the Karl Kirchgessner Foundation, and the Brinson Foundation. We thank Marla Feller from the University of California at Berkeley for Drd4 -GFP mice.

The authors declare no competing financial interests.

Correspondence should be addressed to Wei Wei, Department of Neurobiology, The University of Chicago, $947 \mathrm{E}$. 58th St., MC0928, Chicago, IL 60637. E-mail:weiw@uchicago.edu.

DOI:10.1523/JNEUROSCI.0933-15.2015

Copyright $\odot 2015$ the authors $\quad 0270-6474 / 15 / 3513219-14 \$ 15.00 / 0$ motion. DSGCs receive synaptic inputs from glutamatergic bipolar cells and starburst amacrine cells (SACs), a class of retinal interneuron that corelease GABA and acetylcholine (Brecha et al., 1988; Kosaka et al., 1988; Vaney and Young, 1988; O’Malley and Masland, 1989; Euler et al., 2002; Lee et al., 2010). In wholecell voltage-clamp recordings, the excitatory inputs onto DSGCs are stronger during motion in the preferred direction, whereas the inhibitory inputs are stronger during motion in the null direction (Taylor and Vaney, 2002; Fried et al., 2005; Lee et al., 2010; Park et al., 2014). Furthermore, during preferred-direction motion, the inhibitory inputs lag behind the excitatory inputs due to the spatially offset inhibition relative to excitation (Fried et al., 2002; Taylor and Vaney, 2002).

Stronger inhibition elicited by null-direction motion is the central component of all existing models of direction selectivity in the retina. Directional inhibitory inputs onto DSGCs arise 
from the synergistic action of two mechanisms. The first mechanism is the asymmetric wiring between SACs and DSGCs: SAC processes that are oriented toward the null direction provide the majority of inhibition to a given DSGC (Fried et al., 2002; Lee et al., 2010; Briggman et al., 2011; Wei et al., 2011; Yonehara et al., 2011). The second mechanism is direction-selective output of SAC processes: presynaptic varicosities in SAC processes are preferentially activated by motion in the centrifugal direction (Euler et al., 2002; Lee and Zhou, 2006; Hausselt et al., 2007; Oesch and Taylor, 2010). Inhibitory inputs onto DSGCs are stronger in the null direction because motion in that direction is centrifugal for null-direction-oriented SAC processes and thereby causes maximal GABA release onto DSGC dendrites. In contrast, motion in the preferred direction is centripetal for null-direction-oriented SAC processes and thereby evokes less GABA release and consequently weaker inhibition onto DSGCs. Although directionselective inhibitory inputs onto DSGCs are well established in in both rabbit and mouse retinas, whether it is indispensable for direction selectivity has not been tested directly by loss-offunction studies.

Unlike the well established role of inhibition, the role of the direction-selective excitation that impinges onto DSGCs during image motion remains poorly understood and controversial. Although stronger excitation onto DSGCs when motion is in the preferred direction has been observed consistently in voltageclamp experiments (Taylor and Vaney, 2002; Fried et al., 2005; Lee et al., 2010; Park et al., 2014), the neuronal substrate that implements this direction-selective excitation has not been found. This has raised concern about the limitations of the voltage-clamp technique: the apparent reduction in excitatory conductances during null-direction motion might be caused by electrotonic interactions between the large inhibitory conductance and the excitatory conductance under the condition of imperfect space clamp (Poleg-Polsky and Diamond, 2011; Vaney et al., 2012; Park et al., 2014). How can the pattern of excitatory inputs onto DSGCs be isolated from the influence of inhibitory conductances during motion stimuli? Do other synaptic mechanisms such as direction-selective excitation and temporally offset inhibition contribute to DSGC's directional spiking or is asymmetric inhibition indispensable for direction selectivity? We addressed these questions by performing a loss-of-function study. Using transgenic mice, we eliminated the direction tuning of inhibitory inputs onto DSGCs by reducing the strength of inhibition in the null direction. We then examined direction selectivity in DSGCs when their inhibitory inputs became isotropic.

\section{Materials and Methods}

Mice. Vgat ${ }^{\text {flox/flox }}$ mice $($ Slc32al<tm1Lowl $>/ J)$, ChAT-IRES-Cre mice

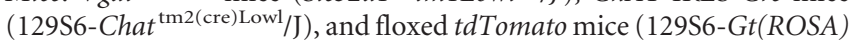

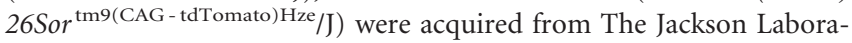
tory. Drd4-GFP mice were originally developed by MMRRC (http:// www.mmrrc.org/strains/231/0231.html) in the Swiss Webster background, subsequently backcrossed to C57BL/6 background, and were obtained from Dr. Marla Feller at the University of California-Berkeley. All strains were backcrossed to the C57BL/6 background in our laboratory and crossed to each other to create the lines used in this study. Mice of both sexes between postnatal days 18 and 35 were used for paired recording experiments and those at postnatal days $24-35$ were used for light response experiments. All procedures to maintain and use mice were in accordance with the University of Chicago Institutional Animal Care and Use Committee, the National Institutes of Health's Guide for the Care and Use of Laboratory Animals, and the Public Health Service Policy.

Immunocytochemistry. Mice were anesthetized with isoflurane and decapitated. The eyes were removed and fixed in $4 \%$ PFA in PBS overnight at $4^{\circ} \mathrm{C}$. Serial coronal sections with a thickness of $12 \mu \mathrm{m}$ were obtained using a cryostat (Leica) and mounted on Superfrost slides (Fisher Scientific). Nonspecific immunoreactivity was suppressed by incubating samples in $10 \%$ bovine serum albumin (BSA, Sigma-Aldrich). Primary antibodies included guinea pig anti-Vgat (SYSY, 1:500) and goat antiVesicular Acetylcholine Transporter (VAChT; Millipore, 1:1000). Primary antibodies were diluted in PBS with 5\% BSA and $0.2 \%$ Triton $\mathrm{X}-100$, applied to the sections and incubated overnight at $4^{\circ} \mathrm{C}$. Sections were then washed four times for 20 min each with PBS containing 5\% BSA, $0.2 \%$ Triton X-100. Secondary antibodies Alexa 594- or Alexa 647conjugated goat anti-guinea pig (Invitrogen, 1:300) and Alexa 488conjugated donkey anti-goat (Invitrogen, 1:300) were applied to the sections and incubated for $2 \mathrm{~h}$ at room temperature. The samples were then washed four times for 20 min each with PBS. All sections were counterstained with Hoechst 33258 (Sigma-Aldrich). Image data were collected with a Leica TCS SP5 confocal microsystem.

Dual whole-cell patch-clamp recording. Mice were anesthetized with isoflurane and decapitated. The retinas were isolated in oxygenated artificial CSF (ACSF) at room temperature containing the following (in $\mathrm{mm}$ ): $119.0 \mathrm{NaCl}, 26.2 \mathrm{NaHCO}_{3}, 11 \mathrm{D}$-glucose, $2.5 \mathrm{KCl}, 1.0 \mathrm{~K}_{2} \mathrm{HPO}_{4}, 2.5$ $\mathrm{CaCl}_{2}$, and $1.3 \mathrm{MgCl}_{2}$. The isolated retinas were then cut into dorsal or ventral halves and mounted ganglion-cell-layer-up on top of a $1 \mathrm{~mm}^{2}$ hole in a small piece of filter paper (Millipore). The orientation of the preferred direction (posterior) of Drd4-GFP-positive neurons was noted for each piece. Dual whole-cell voltage-clamp recordings from SACs and posterior DSGCs (pDSGCs) were performed in oxygenated ACSF in the presence of $0.05 \mathrm{~mm}$ D-AP5 and $0.02 \mathrm{~mm}$ DNQX disodium salt. Recording electrodes of 3-5 $\mathrm{M} \Omega$ were filled with a cesium-based internal solution containing the following (in mM): $110 \mathrm{CsMeSO}_{4}, 2.8 \mathrm{NaCl}, 4$ EGTA, 5 TEA-Cl, 4 adenosine 5 '-triphosphate (magnesium salt), 0.3 guanosine 5 '-triphosphate (trisodium salt), 20 HEPES, 10 phosphocreatine (disodium salt), $5 \mathrm{~N}$-ethyllidocaine chloride (QX314), 0.025 Alexa Fluor 488 (for SACs), and 0.025 Alexa Fluor 594 (for pDSGCs), pH 7.25. Neurons were visualized with transmitted visible light from a halogen bulb, a video camera, and a monitor. tdTomato-labeled SACs and GFP-labeled pDSGCs were identified with epifluorescence imaging (X-Cite) or twophoton microscope (Bruker) under a water-immersion objective $(60 \times$, LUMPlanFl/IR; Olympus). Data were acquired using PCLAMP 10 recording software and a Multiclamp 700B amplifier (Molecular Devices), low-pass filtered at $4 \mathrm{kHz}$, and digitized at a sampling rate of $10 \mathrm{kHz}$. The evoked IPSCs and EPSCs in pDSGCs were isolated by holding the cells at reversal potentials for these conductances $(0 \mathrm{mV}$ for GABAergic, -60 $\mathrm{mV}$ for cholinergic). The reversal potentials were calculated and then experimentally confirmed by obtaining current-voltage relationships of pharmacologically isolated GABAergic and cholinergic currents in pDSGCs. Only recordings with series resistances $<20 \mathrm{M} \Omega$ were used. Liquid junction potential was corrected.

Uncaging of Rubi-GABA. $10 \mu \mathrm{M}$ Rubi-GABA (Tocris Bioscience) was bath applied to the retinas and protected from visible light. A collimated blue LED (470 nm; Thor Laboratories) was flashed for $100 \mathrm{~ms}$ through a $60 \times$ objective onto a $400-\mu \mathrm{m}$-diameter area of the retina centered in the soma of the DSGC. Uncaging response was measure by whole-cell voltage-clamp recordings from DSGCs at $0 \mathrm{mV}$ in the presence of $300 \mu \mathrm{M}$ cadmium chloride (Sigma-Aldrich).

Two-photon targeted recording and imaging of GFP-positive neurons for light response. A white, monochromatic organic light-emitting display (OLEDXL, eMagin; $800 \times 600$ pixel resolution, $60 \mathrm{~Hz}$ refresh rate) was controlled by an Intel Core Duo computer with a Windows 7 operating system. The moving bar stimulus was generated by MATLAB and the Psychophysics Toolbox and projected through the condenser lens of the two-photon microscope onto the photoreceptor layer, centering on the pDSGC soma. White bars in a dark background moved in 12 pseudorandomly chosen directions spaced at 30 degree intervals at a speed of 500 $\mu \mathrm{m} / \mathrm{s}$ on the retina and were presented in three to five repetitions. The percent stimulus contrast $\left(L_{\text {stimulus }}-L_{\text {background }}\right) /\left(L_{\text {stimulus }}+L_{\text {background }}\right)$ was $80-100 \%$. A detailed protocol of the two-photon targeted recording of light response can be found in Wei et al. (2010).

Mice were anesthetized with isoflurane and decapitated after dark adaptation. Under infrared illumination, retinas were isolated from the 
pigment epithelium in oxygenated Ames' medium (Sigma-Aldrich), cut into dorsal and ventral halves, and mounted onto filter papers as described above. Retinas were kept in darkness at room temperature in Ames' medium bubbled with $95 \% \mathrm{O}_{2} / 5 \% \mathrm{CO}^{2}$ until use ( $\left.0-7 \mathrm{~h}\right)$. During recordings, the retinas were perfused with oxygenated Ames at $32-33^{\circ} \mathrm{C}$. Cells were visualized with infrared light $(>900 \mathrm{~nm})$ and an IR-sensitive video camera (Watec). GFP-positive cells were identified by a twophoton microscope (Bruker) and a Ti:sapphire laser (Chameleon Ultra II; Coherent Technologies) tuned to $920 \mathrm{~nm}$. First, an electrode of 3-5 $\mathrm{M} \Omega$ was filled with Ames' medium for loose patch recordings of spikes; then, the electrode was carefully removed and a new electrode filled with the cesium-based internal solution was used to obtain whole-cell voltageclamp recordings from the same cell using the same method and criteria as those used in dual patch-clamp experiments. Light-evoked IPSCs and EPSCs in pDSGCs were isolated by holding the cells at $0 \mathrm{mV}$ and -60 $\mathrm{mV}$, respectively. For Figure 6G, $0.0125 \mathrm{mM}$ gabazine (SR-95531, Tocris Bioscience) was applied. At the end of recording, an image stack of the Alexa Fluor 488-filled pDSGCs was acquired with the two-photon microscope at $z$ intervals of $1.5 \mu \mathrm{m}$ and resampled three times for each $z$-plane using a $60 \times$ objective (Olympus LUMPlanFl/IR $60 \times / 0.90 \mathrm{~W}$ ). Images were acquired to cover the entire dendritic field of the cell. To isolate cholinergic component of the light responses, EPSCs were recorded before and after bath application of $0.008 \mathrm{~mm} \mathrm{DH} \beta \mathrm{E}$ (Tocris Bioscience) for each cell.

Analysis of electrophysiological data. Data were analyzed using custom protocols in MATLAB. Three to five raw response traces were recorded and averaged to obtain the mean response at each stimulus direction. The peak amplitude of the currents evoked by the leading (On) and treading (Off) edges of the bright bar were used for calculating $\mathrm{P} / \mathrm{N}$ or N/P ratios. To analyze the relative timing between excitation and inhibition, we first determined the time window of the On response. Light-evoked EPSCs return to baseline after the leading edge of the bar leaves the receptive field. Therefore, the start $\left(t_{\text {start }}\right)$ and end $\left(t_{\text {end }}\right)$ times can be determined reliably. Light-evoked IPSCs usually contain a sustained component that does not return to the baseline after the leading edge leaves the receptive field. Therefore, the end time of IPSCs is set to equal the end time of EPSCs. The time of peak ( $\left.t_{\text {peak }}\right)$, as well as the time at center of mass of the charge transfer $\left(t_{\mathrm{cm}}\right)$, during this time window were determined for synaptic currents recorded at the null and preferred directions. $t_{\mathrm{cm}}$ is defined as follows: $\frac{\int_{t_{\text {start }}}^{t_{\text {end }}} I(t) \cdot t d t}{\int_{t_{\text {end }}} I(t) d t}$ (adapted from Agmon-Snir and Segev, 1993). For each direction, the relative difference in the timing between EPSC peak and IPSC peak $(\Delta t)$ was calculated by subtraction. The temporal offset was then determined by $\left(\Delta t_{\text {preferred }}-\Delta t_{\text {null }}\right)$, with a positive value indicating delayed inhibition in the preferred direction. Similar calculations were done to determine the temporal offset using $t_{\mathrm{cm}}$ for EPSCs and IPSCs. For Figure 8, the cholinergic component of the light responses was isolated by subtracting the averaged EPSCs (three trials per direction) after $\mathrm{DH} \beta \mathrm{E}$ application from the averaged traces before addition of $\mathrm{DH} \beta \mathrm{E}$.

Analysis of dendritic morphology. On and Off dendritic arbors of pDSGCs were traced from two-photon image stacks using ImageJ. Each dendritic layer was divided into halves based on the preferred direction of the cell's spiking activity. A line perpendicular to the preferred direction was drawn at the position of the cell body to separate the dendritic arbors into the preferred side and null side regions. The total dendritic length in each region was measured from the traced skeleton. The area of the dendritic arbors was determined by first connecting the tips of the dendrites to a polygon and then fitting it to a cubic spline curve.

Statistical analysis. Grouped data are presented as mean \pm SEM. Statistical analysis was performed using MATLAB. Linear regression with an $F$ test (two-sided) was used for Figures 6 and 9. A two-sample KolmogorovSmirnov test was used for Figure 4C. Cross-correlation was performed for Figure 7. For the rest of the figures, data were tested for normality and statistical differences were examined using one-way ANOVA and post hoc comparisons using Student's $t$ test with Bonferroni corrections. The statistical significance of spike-tuning curves during motion stimuli was determined by the bootstrapping analysis (Efron and Tibshirani, 1994;
Stark and Abeles, 2005). For each cell, the spike counts during moving bar stimuli (12 directions, three to five repetitions) were randomly sampled and replaced using a bootstrapping algorithm 10,000 times. The null hypothesis is that spiking activity is isotropic during moving bar stimuli. direction-selective index (DSI) and vector sum values were computed for each resampled dataset. The nonparametric $95 \%$ confidence limits were determined from the distribution of DSI and vector sum values of the bootstrapped datasets. To be classified as direction selective, a cell needs to have significant DSI and vector sum values and a DSI $\geq 0.2$.

\section{Results}

Asymmetric inhibition between SACs and DSGCs is impaired when the Vgat gene is deleted from SACs

We generated a conditional knock-out mouse line in which the vesicular GABA transporter (Vgat) gene is selectively deleted in SACs in the retina. This line contains the following transgenes: homozygous floxed Vgat allele ( ggat $^{\text {flox/flox }}$ ) to replace the endogenous Vgat gene, a choline acetyltransferase (ChAT)-IRESCre knock-in allele for SAC-specific Cre expression (acronym: $C$ ), a floxed $t d$ Tomato transgene to report functional Cre protein expression (acronym: T), and a Drd4-GFP transgene to label On-Off DSGCs that prefer motion in the posterior direction (pDSGCs; acronym: D; Huberman et al., 2009; Fig. 1A). In these $V g a t{ }^{\text {flox/flox }} C T D$ mice, tdTomato expression was turned on and the Vgat gene was deleted in SACs, whereas GFP was expressed in pDSGCs (Fig. 1B). We first confirmed that the VGAT protein is knocked down in SAC processes by double immunostaining for Vgat and VAChT in Vgat ${ }^{\text {flox/flox }} \mathrm{C}$ mice. SAC processes in $V g a t^{\text {lox/flox }} C$ mice stratify precisely in S2 and S4, where VGAT immunofluorescence signal is absent (Fig. 1C). We did not detect changes in SAC and pDSGC dendritic morphology (Fig. 1D,E) or in gross anatomical organization of the retina in $\operatorname{Vgat}^{\text {flox/flox }} \mathrm{C}$ mice.

We then examined GABA release from SACs by performing paired whole-cell voltage-clamp recordings between SACs and pDSGCs in control (CTD) and $V g a t^{\text {flox/flox }} C T D$ mice. We included all SAC-pDSGC pairs with an intersoma distance of 60-80 $\mu \mathrm{m}$ that had overlapping dendritic arbors and clear cholinergic EPSCs. In control mice, SACs from the null side of pDSGCs provide strong GABAergic inputs to pDSGCs, whereas SACs from the preferred side are weakly connected (Fig. $2 A-D$ ). However, in $V g a t^{\text {flox/flox }}$ CTD mice, both null and preferred side SAC-pDSGC pairs exhibit severe loss of GABAergic transmission (Fig. $2 A-D$ ). Fifty percent of the preferred side pairs and $32 \%$ of the null side pairs show no detectable GABAergic connections (Fig. 2A). The rest of the pairs show residual GABAergic responses (Fig. $2 B, C$ ), probably due to GABA release from SACs through residual VGAT protein and/or compensatory mechanisms (Wojcik et al., 2006; Tritsch et al., 2012). However, the strength of GABAergic connections in null side pairs is significantly reduced compared with that of null side pairs in the control group (Fig. 2D, control null vs KO null). In Vgat ${ }^{\text {flox/flox }} C T D$ mice, the IPSCs in null side pairs are still slightly stronger on average than those in preferred side pairs, but this difference is not statistically significant (Fig. $2 \mathrm{D}$, KO pref vs $\mathrm{KO}$ null). We also noted that the amplitude of IPSCs in null side pairs in $V g a t^{\text {flox/flox }} C T D$ mice is similar to that of preferred side pairs in the control group (Fig. 2D). Therefore, the asymmetric GABAergic transmission between SAC and pDSGCs is significantly disrupted in these mice. In contrast, the amplitude of cholinergic EPSCs in pDSGCs is similar in control and $V g a t^{\text {flox/flox }} C T D$ mice (Fig. 2E), indicating that GABA, but not acetylcholine, release 
from SACs has been selectively affected in $V g a t^{\text {flox/flox }} C T D$ mice.

To determine whether the expression of GABA receptors on pDSGCs is altered by knocking out Vgat in SACs, we performed uncaging of Rubi-GABA onto a $400-\mu \mathrm{m}$-diameter area of the retina centered on pDSGC somas and recorded the GABAergic responses in pDSGCs from control and $V g a t^{\text {flox/flox }} C T D$ mice. The cells from both groups show uncaging-induced GABAergic currents with similar peak amplitude and charge transfer (Fig. $2 F, G$ ). This suggests that disrupting GABA release from SACs in $V g a t^{\text {flox/flox }}$ CTD mice does not lead to a drastic change in the amount of GABA receptor expression on pDSGCs.

Light response of pDSGCs in the absence of direction-selective inhibition

How do the pDSGCs of $V g a t^{\text {flox/flox }} C T D$ mice respond to moving stimuli in the absence of asymmetric inhibition between SACs and pDSGCs? We addressed this question by performing loose-patch and whole-cell voltage-clamp recordings of Drd4-GFP-positive pDSGCs in control mice ( $V g a t^{\text {flox/flox }} T D, V g a t^{\text {flox/flox }} D$, and $C T D)$ and in $V g a t^{\text {flox/flox }} C T D$ mice to monitor responses during moving bar stimuli. We also filled the cells with Alexa Fluor 594 after recordings to acquire twophoton image stacks of the recorded pDSGCs. This allowed us to collect data from Drd4-GFP-positive cells that exhibit the characteristic morphology of On-Off DSGCs, namely, looping dendritic arbors that costratify with tdTomato-labeled SAC processes in the S2 and S4 sublaminae (Berson, 2008).

First, we examined the pattern of inhibitory inputs onto pDSGCs in Vgat ${ }^{\text {flox/flox }}$ CTD mice. In control mice, the leading and trailing edges of a moving bright bar in the null direction evoked stronger IPSCs than in the preferred direction in all pDSGCs (Fig. $3 A-C$ ). In $V g a t^{\text {flox/flox }} C T D$ mice, a small number of DSGCs exhibited no detectable light-evoked IPSC (15\%, 3 of 20 cells) and the rest of the DSGCs showed residual IPSCs (Fig. 3A). However, the residual IPSC amplitude and charge transfer in the null and preferred directions were not significantly different (Fig. $3 B, C$ ). The amplitude of the residual IPSCs in $V g a t^{\text {flox/flox }}$ CTD mice is comparable to that of preferred-direction evoked IPSCs in the control group (Fig. 3C). This is consistent with the loss of asymmetric GABAergic transmission between SACs and pDSGCs observed in paired recordings (Fig. 2D).

Next, we investigated whether the spiking activity of pDSGCs is still direction selective in $V g a t^{\text {flox/flox }} C T D$ mice using loose-patch recording during moving bar stimuli. We

A

C

D
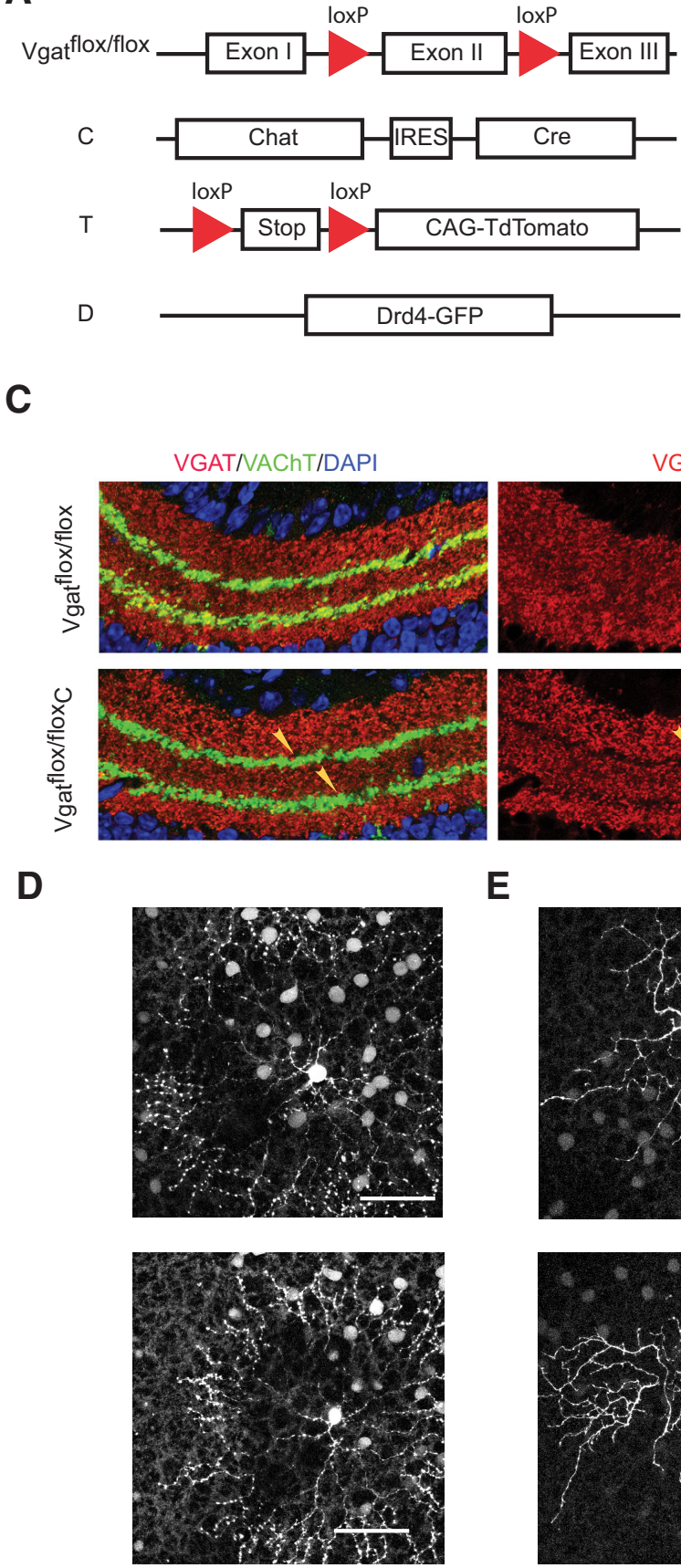

Figure 1. VGAT protein is knocked down in SACs from Vgat conditional knock-out mice. $A$, Schematic diagram showing the transgenes in Vgat conditional knock-out mice. $B$, Two-photon image of the ganglion cell layer from a Vgat ${ }^{\text {flox/flox }}$ CTD retina showing a Drd4-GFP labeled pDSGC (red arrowhead) and tdTomato-labeled SACs (red somas). Scale bar, $10 \mu \mathrm{m}$. C, Left, Vgat ${ }^{\text {flox/flox }}$ retina (as a control) and Vgat ${ }^{\text {flox/flox }}$ C retina immunostained for VGAT, VAChT and DAPI. Right: same images showing the VGAT signal only. Scale bar, $20 \mu \mathrm{m}$. Arrows indicate the $\$ 2$ and $S 4$ sublaminae that contain SAC dendrites. $D$, Two On SACs from a Vgat ${ }^{\text {flox/flox }}$ CTD retina filled with Alexa Fluor 594 to show their radial symmetric processes. The dimmer somas in the background are some unfilled SACs expressing tdTomato in the same focal planes. Scale bars, $50 \mu \mathrm{m} . E$, $0 \mathrm{n}$ and Off dendritic arbors from a pDSGC in a Vgat ${ }^{\text {flox/flox }}$ CTD retina filled with Alexa Fluor 488. Scale bars, $50 \mu \mathrm{m}$. used the normalized vector sum of spiking activity and DSI, defined as $\left(N_{\text {pref }}-N_{\text {null }}\right) /\left(N_{\text {pref }}+N_{\text {null }}\right)$, where $N$ is the total number of spikes evoked by the leading and trailing edges of the moving bar. The cells were filled with Alexa Fluor 594 after loosepatch recordings for two-photon imaging of their dendritic morphology. To prevent sampling bias, we included all Drd4GFP-positive pDSGCs with bistratified dendrites at S2 and S4 in 
A
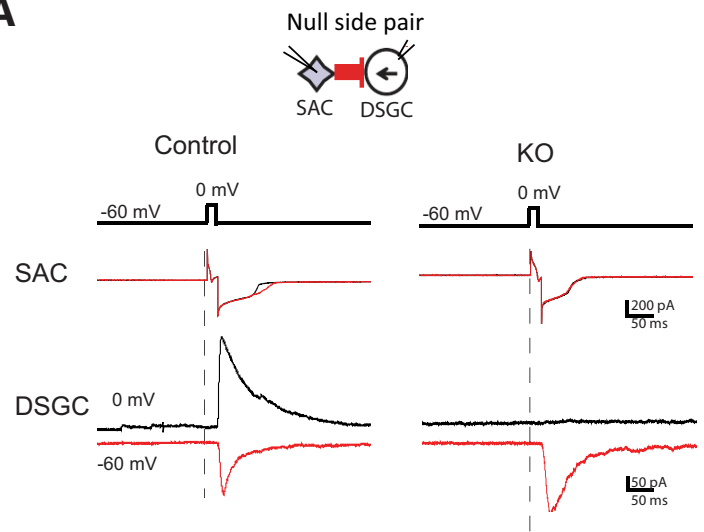

B

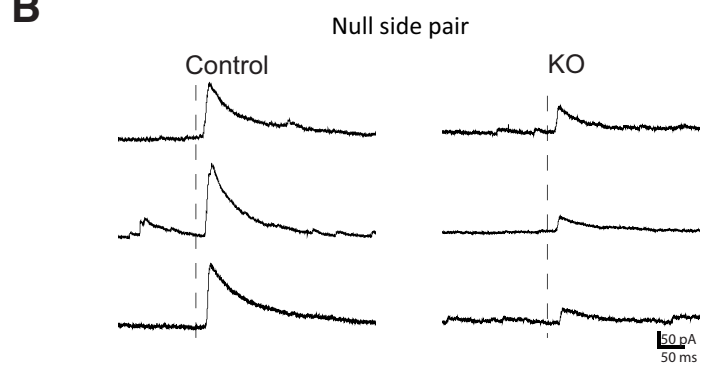

C

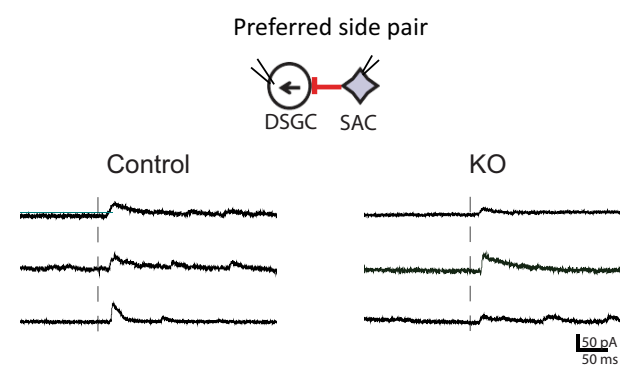

D

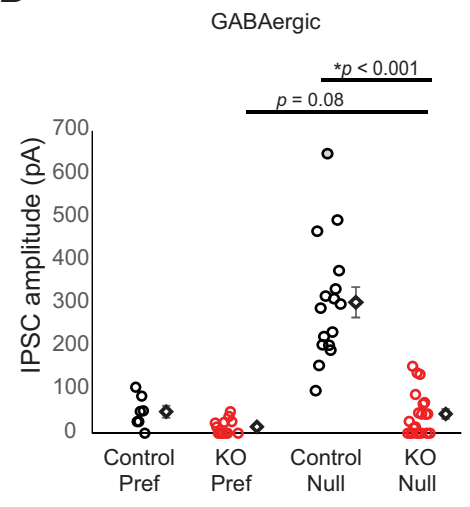

F

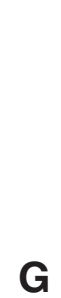

E

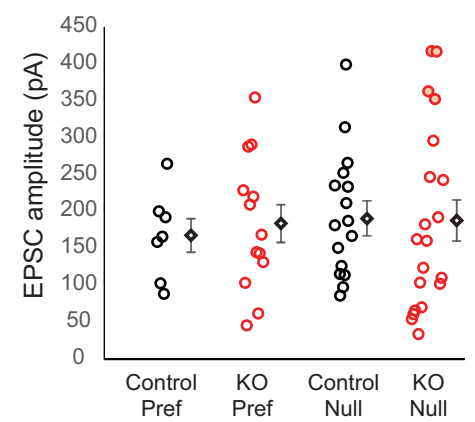

G

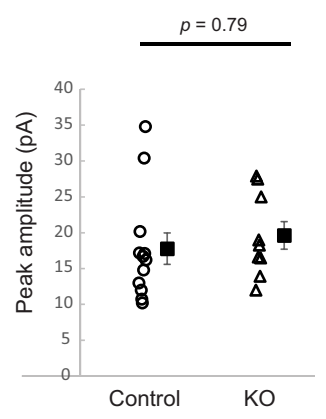

$\mathrm{KO}$
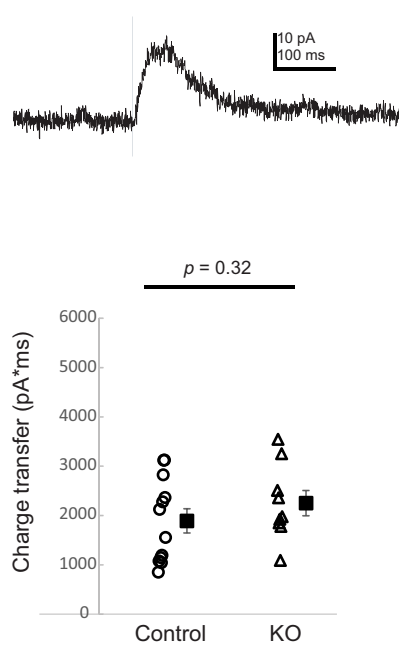

Figure 2. Asymmetric inhibition between SACs and pDSGCs is impaired in Vgat flox/flox CTD mice. A, Voltage-clamp traces from null-side SAC-DSGC pairs in CTD (Control) and Vgat ${ }^{\text {flox/flox }}$ CTD (KO) mice showing cholinergic EPSCs (red) and GABAergic IPSCs (black) evoked in DSGCs by depolarizing SACs. Dashed lines indicate the onset of voltage step in SACs. Top schematic diagram shows the relative soma locations in null-side pairs. Black arrow indicates the DSGC's preferred direction. Thicker red arrow indicates stronger GABAergic inputs from null-side SAC. B, Examples of null-side SAC-evoked IPSCs of pDSGCs in Control and KO groups exhibiting residual inhibition. C, Examples of preferred-side SAC-evoked IPSCS in Control and KO groups exhibiting residual inhibition. Top schematic diagram shows the relative soma locations in preferred-side pairs. D, Summary plot of IPSC peak amplitudes in pDSGCs evoked by preferred and null side SACs. Individual data points and statistical summary (mean \pm SEM) are shown. Control-Pref: $49.5 \pm 13.7 \mathrm{pA}, n=7$ cells, 5 mice; Control-Null: $299.7 \pm 35.0$ pA, $n=16$ cells, 8 mice; KO-Pref: $14.8 \pm 5.1$ pA, $n=13$ cells, 8 mice; K0-Null: $44.3 \pm 11.3 \mathrm{pA}, n=20$ cells, 11 mice. $\boldsymbol{E}$, As in $\boldsymbol{D}$, summary plot of cholinergic EPSC peak amplitudes. Control-Pref: $167.3 \pm 22.4 \mathrm{pA}, n=7$ cells, 5 mice; Control-Null: $204.0 \pm 23.4 \mathrm{pA}, n=16$ cells, 8 mice; K0-Pref: $183.3 \pm 25.0 \mathrm{pA}, n=13$ cells, 8 mice; K0-Null: $187.2 \pm 27.4$ pA, $n=20$ cells, 11 mice. $\boldsymbol{F}$, Examples of IPSCs in pDSGCs evoked by uncaging of Rubi-GABA. Synaptic transmission was blocked by $300 \mu \mathrm{m} \mathrm{CdCl}_{2}$. Vertical lines indicate the start of illumination by a $470 \mathrm{~nm}$ LED of a $400 \mu \mathrm{m}$ spot centered on the DSGC. G, Summary plot of IPSC peak amplitudes (left) and charge transfer (right) in pDSGCs during uncaging of Rubi-GABA. Individual data points and statistical summary (mean \pm SEM) are shown. Control: peak amplitude $17.8 \pm 2.2 \mathrm{pA}$, charge transfer $1892.7 \pm 245.6 \mathrm{pA} / \mathrm{ms}, n=12$ cells, 4 mice; K0: peak amplitude $19.6 \pm 1.9 \mathrm{pA}$, charge transfer $2253.5 \pm 254.8 \mathrm{pA} / \mathrm{ms}, n=9$ cells, 3 mice.

our analysis without preselection of cells based on their DSI values. In the control group, the most weakly tuned pDSGC has a DSI value of 0.23 (Fig. $4 A, B$, cell \#1). To determine whether a cell shows statistically significant direction selectivity, we performed a bootstrapping analysis with the null hypothesis that spiking activity are uniform in all motion directions (see Materials and Methods). All cells in the control group, including the one with DSI of 0.23 , showed significant direction selectivity in the bootstrapping analysis. In $V g a t{ }^{\text {flox/flox }} C T D$ mice, many pDSGCs have DSI values $<0.2$ and tuning curves that are not apparently direction selective (Fig. 4A, B, cell \#3). Therefore, we use the following two criteria to classify pDSGCs in $\mathrm{Vgat}{ }^{\text {flox/flox }} \mathrm{CTD}$ mice as direction selective: (1) a DSI cutoff of 0.2 and (2) the bootstrapping analysis $(p<0.05)$. According to this method, pDSGCs in
$V g a t{ }^{\text {flox/flox }} C T D$ mice are divided into non-direction-selective (non-DS) and direction-selective (DS) groups. We found that $49 \%$ ( 16 of 33 cells) of these pDSGCs belong to the non-DS group and lose direction selectivity in their spiking activity (Fig. 4A). This indicates that asymmetric inhibition between SACs and DSGCs is indispensable for direction selectivity in some cells. However, the remaining $51 \%$ of pDSGCs (17 of 33 cells) in $V g a t{ }^{\text {flox/flox }}$ CTD mice belong to the DS group and show direction-selective spiking (Fig. $4 A, B$ ), although their spike DSI and vector sum values are significantly reduced compared with those in the control group (Fig. 4C). Impaired direction selectivity of all pDSGCs in Vgat ${ }^{\text {flox/flox }}$ CTD mice demonstrates that direction-selective inhibition is required for optimal tuning, but it is notable that residual direction selectivity is imple- 
A

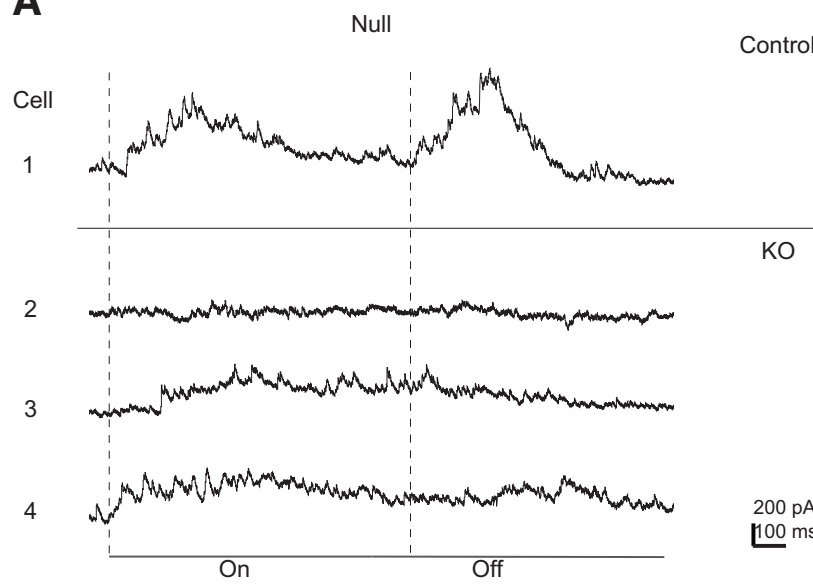

Preferred

B
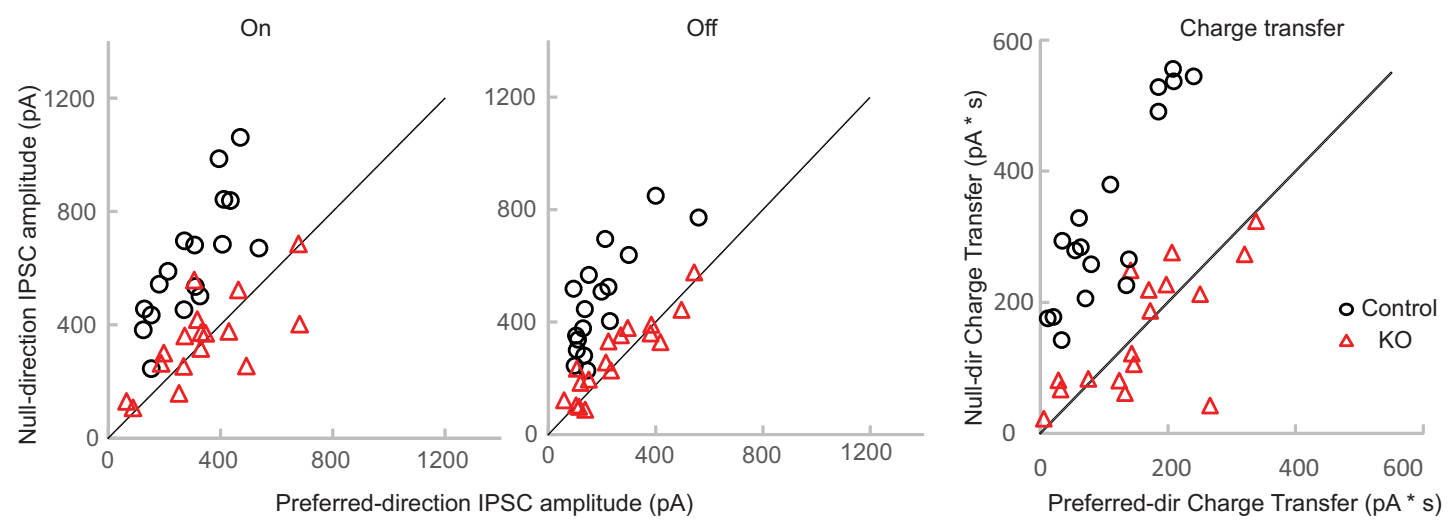

C

On

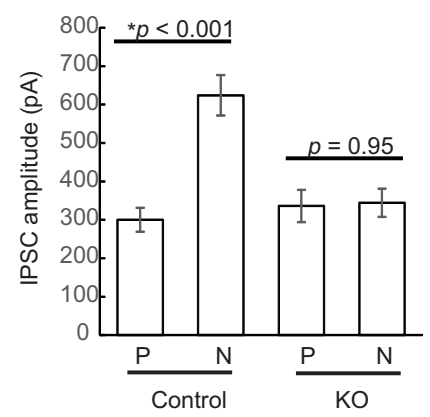

Off

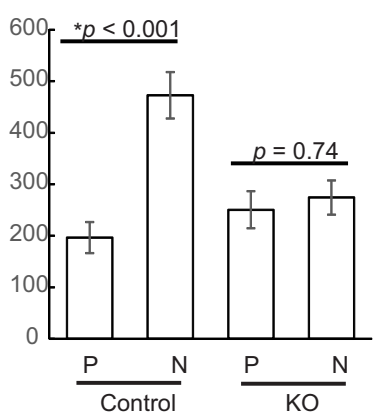

Charge transfer

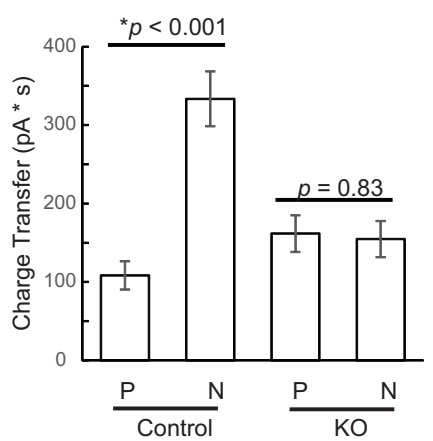

Figure 3. Inhibitory inputs onto pDSGCs in Vgat ${ }^{\text {flox/flox }}$ CTD mice lose direction selectivity. $A$, Voltage-clamp recordings of a pDSGC in Vgat ${ }^{\text {flox/flox }}$ TD (Control, Cell 1) and of 3 cells in Vgat ${ }^{\text {flox/flox }}$ CTD mice (K0, Cell 2-4) showing inhibitory currents evoked by the leading (On) and trailing (Off) edges of a bright bar moving in the preferred and null directions. Dashed lines separate the leading and trailing edge responses. $\boldsymbol{B}$, For the $\mathrm{On}$ (left) and Off (right) components indicated in $(\boldsymbol{A})$, summary plots of IPSC peak amplitudes and total charge transfer evoked by null-direction motion against those evoked by preferred-direction motion. Control mice include Vgat ${ }^{\text {flox/flox } T D, V g a t}{ }^{\text {flox/flox }} D$, and $C T D$ for this figure and subsequent figures. Diagonal lines are unity lines. $C$, Summary plots showing IPSC amplitudes and total charge transfer in the preferred and null directions for control ( $n=17$ cells, 10 mice) and KO ( $n=17$ cells, 10 mice) groups. On: control preferred $300.3 \pm 31.1$ pA, control null $624.1 \pm 52.8 \mathrm{pA}, \mathrm{KO}$ preferred $336.2 \pm 42.0 \mathrm{pA}, \mathrm{KO}$ null $344.5 \pm 36.9 \mathrm{pA}$; Off: control preferred $196.3 \pm 30.2 \mathrm{pA}$, control null $472.7 \pm 45.0 \mathrm{pA}, \mathrm{KO}$ preferred $250.4 \pm 36.0 \mathrm{pA}$, KO null $274.3 \pm 33.2 \mathrm{pA}$; total charge transfer: control preferred $108.3 \pm 18.0 \mathrm{pA} / \mathrm{s}$, control null $333.5 \pm 34.9 \mathrm{pA} / \mathrm{s}$, KO preferred $161.7 \pm 23.3 \mathrm{pA} / \mathrm{s}, \mathrm{KO}$ null $154.6 \pm 23.3 \mathrm{pA} / \mathrm{s}$.

mented in half of the pDSGCs in the absence of asymmetric inhibition. After performing loose-patch recordings, we then performed whole-cell patch-clamp recordings from a subset of the pDSGCs from the control, non-DS, and DS groups to measure their excitatory and inhibitory inputs (Fig. 5).

We first investigated whether residual inhibition in $V g a t^{\text {flox/flox }} C T D$ mice could account for the difference in spiking activity between the non-DS and DS groups. We quantified the directionality of inhibition using the ratio of IPSC amplitudes in response to bars moving in the null and preferred directions $(\mathrm{N} / \mathrm{P})$, where the preferred direction was defined by the angle of the vector sum of the spike-tuning curve. As expected, cells in control mice show high N/P ratios for both On and Off components (Figs. 6A, 5A). However, residual IPSCs in the non-DS and DS groups exhibit 
A

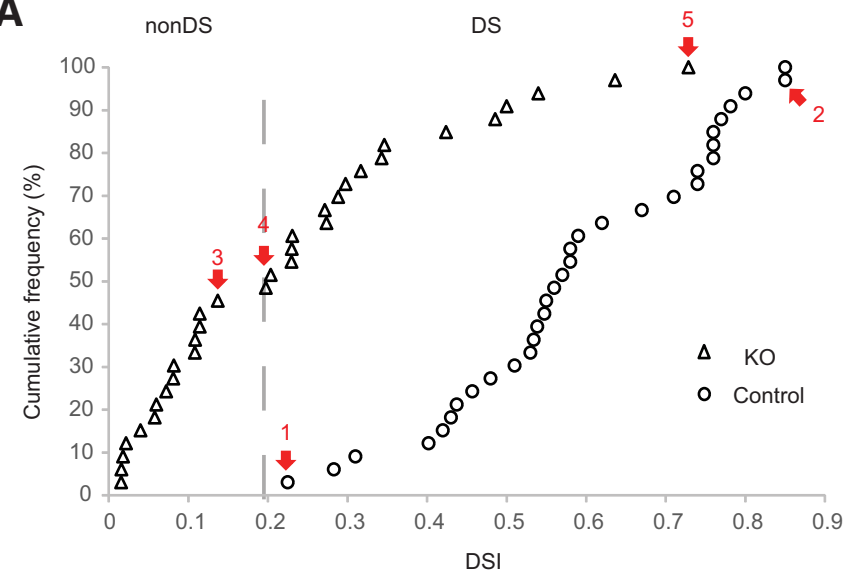

C

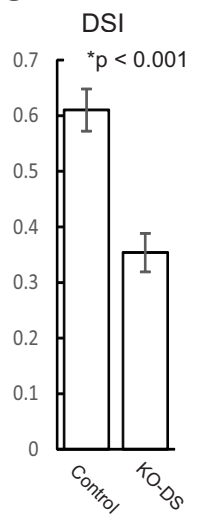

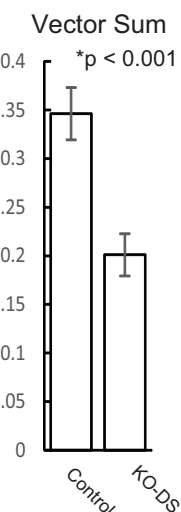

B

Control

KO

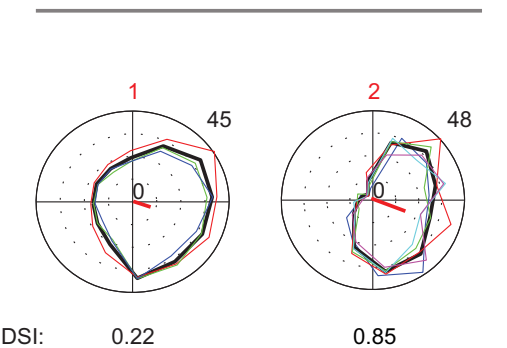

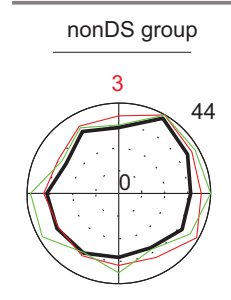

0.11

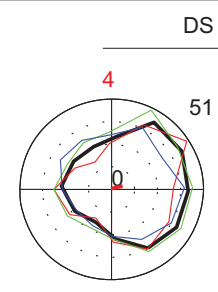

0.20 DS group

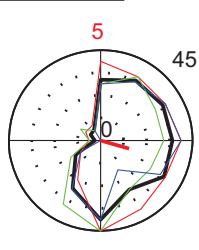

0.73

Figure 4. Spiking activity remains direction selective in a subpopulation of pDSGCs in Vgat ${ }^{\text {floxfflox }}$ (TD mice. $A$, Cumulative frequencies of spike DSI from control and Vgat flox/flox $(T D$ (KO) mice. Dashed line indicates cutoff between non-DS and DS groups of pDSGCs in K0 mice (see Results and Materials and Methods). Numbers 1-5 indicate individual cells belonging to control, non-DS, and DS groups. B, Polar plots and DSI values of spiking activity for cells labeled 1-5 in $A$ illustrate a non-DS cell from a K0 mouse (\#3), weakly tuned cells in control (\#1) and KO (\#4) mice, and strongly tuned cells in control (\#2) and KO (\#5) mice. Colored lines represent individual repetitions and black lines represent the mean number of spikes evoked by bars moving in 12 directions. Red lines in the center represent the vector sum of spiking activity. The maximum number of spikes is shown in the upper right of each plot. C, Summary plot showing DSI and vector sum values in control $(n=$ 33 cells, 20 mice) and KO-DS ( $n=18$ cells, 15 mice) groups. DSI control: $0.59 \pm 0.03$; K0-DS: $0.37 \pm 0.04$; vector sum control: $0.35 \pm 0.03 ;$ KO-DS: $0.20 \pm 0.02$.

similar N/P ratios that are significantly lower than those in control cells (Figs. $6 A, 5 B, C$ ). In addition, there is no positive correlation between the IPSC N/P ratios and the spiking DSI values in the DS group of $V g a t^{\text {flox/llox }} C T D$ mice (Fig. $6 B$ ). This indicates that the directional spiking of pDSGCs in the DS group cannot be explained by the strength of residual inhibitory inputs.

Next, we investigated whether the excitatory inputs onto pDSGCs remain direction selective in $V g a t{ }^{\text {flox/flox }} C T D$ mice. The EPSCs in the control and $V g a t^{\text {flox/flox }} C T D$ mice are of similar amplitude, suggesting that the excitatory inputs onto pDSGCs in Vgat ${ }^{\text {flox/flox }} C T D$ mice are not perturbed by Vgat deletion (Fig. $6 E)$. We used the ratio of EPSC amplitude in the preferred and null directions $(\mathrm{P} / \mathrm{N})$ to quantify the directionality of excitatory inputs. Moving bars evoked nondirectional excitation onto pDSGCs in the non-DS group (Figs. $6 C, 5 B$ ). In contrast, motionevoked excitatory inputs onto pDSGCs in the DS group were still direction selective and tuned to the preferred direction of spiking, similarly to control cells (Figs. $6 C, 5 C$ ). A positive correlation was found between the DSI and EPSC P/N ratio in the DS group (Fig. $6 D$ ). Furthermore, both the spiking activity and the EPSCs of Drd4-GFP-positive neurons remain tuned to the posterior direction in $\mathrm{Vgat}{ }^{\text {flox/flox }}$ CTD mice, similar to those in wild-type retinas (Fig. $6 F$ ). Bath application of the $\mathrm{GABA}_{\mathrm{A}}$ receptor antagonist gabazine significantly reduced the EPSC P/N ratio in both the control and DS groups in Vgat ${ }^{\text {flox/flox }} C T D$ mice (Fig. $6 G$ ), which is consistent with the hypothesis that DS excitation may involve upstream inhibitory mechanisms other than GABA release from SACs (Fried et al., 2005; Lee et al., 2010, but see Discussion).
Together, these results indicate that directionally tuned excitation contributes to direction-selective spiking activity.

Because direction-selective EPSCs in wild-type mice may result from the presence of stronger inhibitory inputs during motion in the null direction under imperfect voltage-clamp conditions, we further assessed whether residual inhibition could account for the directionality of EPSCs in Vgat ${ }^{\text {flox/flox }} C T D$ mice. If inhibitory currents largely account for direction-selective excitation, then both the IPSC peak amplitude in the null direction and the IPSC N/P ratio would be expected to correlate positively with the EPSC P/N ratio. In control mice, no positive correlation is found between the IPSC N/P ratio and EPSC P/N ratio (On: $R^{2}=0.02, p=0.40$; Off: $R^{2}=0.03, p=0.40, n=17$ cells; linear regression with an $F$ test) or between null-direction IPSC peak amplitude and EPSC P/N ratio for the On component $\left(R^{2}=\right.$ $0.15, p=0.12$ ). A weak positive correlation is seen between IPSC amplitude and EPSC P/N ratio for the Off component in control mice $\left(R^{2}=0.33,{ }^{*} p=0.02\right)$, which might be explained by the difficulty in controlling membrane potential in the more distal Off dendritic arbors of pDSGCs and therefore more pronounced space-clamp errors. However, in Vgat ${ }^{\text {flox/flox }} C T D$ mice, there is no positive correlation between the EPSC $\mathrm{P} / \mathrm{N}$ ratio and either the IPSC amplitude (On: $R^{2}=0.34,{ }^{*} p=0.01$, negative correlation; Off: $R^{2}=0.001, p=0.90 ; n=19$ cells) or the IPSC N/P ratio (On: $R^{2}=0.21, p=0.08$; Off: $\left.R^{2}=0.03, p=0.44\right)$. To further rule out the effect of residual inhibition on the directional tuning of pDSGC's spiking activity and EPSCs, we separately analyzed the cells in the DS group with IPSC N/P ratio $\leq 1$. All of cells in this group exhibit direction-selective excitation $[\mathrm{EPSC} \log (\mathrm{P} / \mathrm{N})=$ 
$0.20 \pm 0.04, n=14$, On and Off data are pooled together]. In addition, of the DS group, $\sim 8 \%$ of the pDSGCs showed directionally tuned EPSCs but no detectable stimulus-evoked IPSCs, indicating that direction-selective excitation can be the sole mechanism generating direction selectivity in some pDSGCs in $V$ gat ${ }^{\text {flox/flox }}$ CTD mice. In summary, it is unlikely that imperfect voltage-clamp recording accounts solely for the observed direction selectivity of excitatory inputs. When the inhibitory inputs onto pDSGCs in $V g a t^{\text {flox/flox }} C T D$ mice are abolished or reduced to equal strength during motion in the preferred and null directions, direction selectivity of the spiking activity and of excitatory inputs persists in about half of the pDSGC population.

Because the majority of Drd4-GFPpositive neurons receive residual inhibition in $V g a t^{\text {flox/flox }} C T D$ mice, we examined the relative timing of excitatory inputs and residual inhibitory inputs onto DSGCs during motion stimuli. We measured two parameters: (1) the time of peak current amplitude $\left(t_{\text {peak }}\right)$ and (2) the time at the center of mass of the total charge transfer $\left(t_{\mathrm{cm}}\right)$ (see Materials and Methods). We then calculated the timing difference between EPSCs and IPSCs $(\Delta t)$ evoked by the leading edge of the moving bar in the preferred and null directions. The temporal offset is defined as $\Delta t_{\text {pref }}-$ $\Delta t_{\text {null }}$, with a positive value indicating delayed inhibition in the preferred direction. We did not quantify the temporal delay for the trailing edge response because, in many pDSGCs in ggat $^{\text {flox/ }}$ flox $C T D$ mice, it is difficult to identify precisely the peak time for the Off response due to reduced IPSC amplitude and a sustained component of IPSC between the leading and trailing edge of the moving bar (Fig. 3A). Analysis using $t_{\text {peak }}$ or $t_{\mathrm{cm}}$ yields qualitatively the same results. In the control group, the inhibitory inputs onto pDSGCs were significantly delayed compared with the excitatory inputs during motion in the preferred direction (Figs. 7A, 5A). The temporal offset of inhibitory inputs is absent in the non-DS group (Figs. 7A, 5B). For pDSGCs in the DS group, the residual inhibition is still delayed in the preferred direction motion, but this temporal delay is significantly reduced compared with the control group (Figs. $7 A, 5 C$ ).

How do directional excitation and temporal delay between excitation and inhibition contribute to the spiking activity in $V g a t{ }^{\text {flox/flox }}$ CTD mice? We attempted to address this question by comparing the time course of action potential generation, excitatory and inhibition currents, and the relative difference between excitatory and inhibitory conductances $\left(\Delta g=g_{\mathrm{e}}-g_{\mathrm{i}}\right)$. The recorded traces were divided into $100 \mathrm{~ms}$ bins. The number of action potentials, excitatory and inhibitory currents, and $\Delta g$ are

IPSC
Control B nonDS C DS
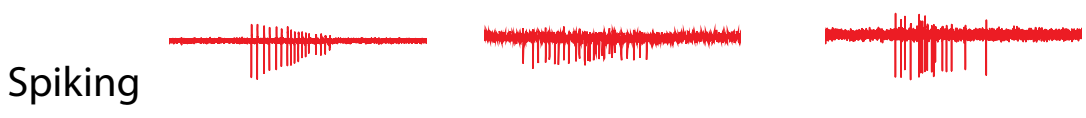

||$T \mid$
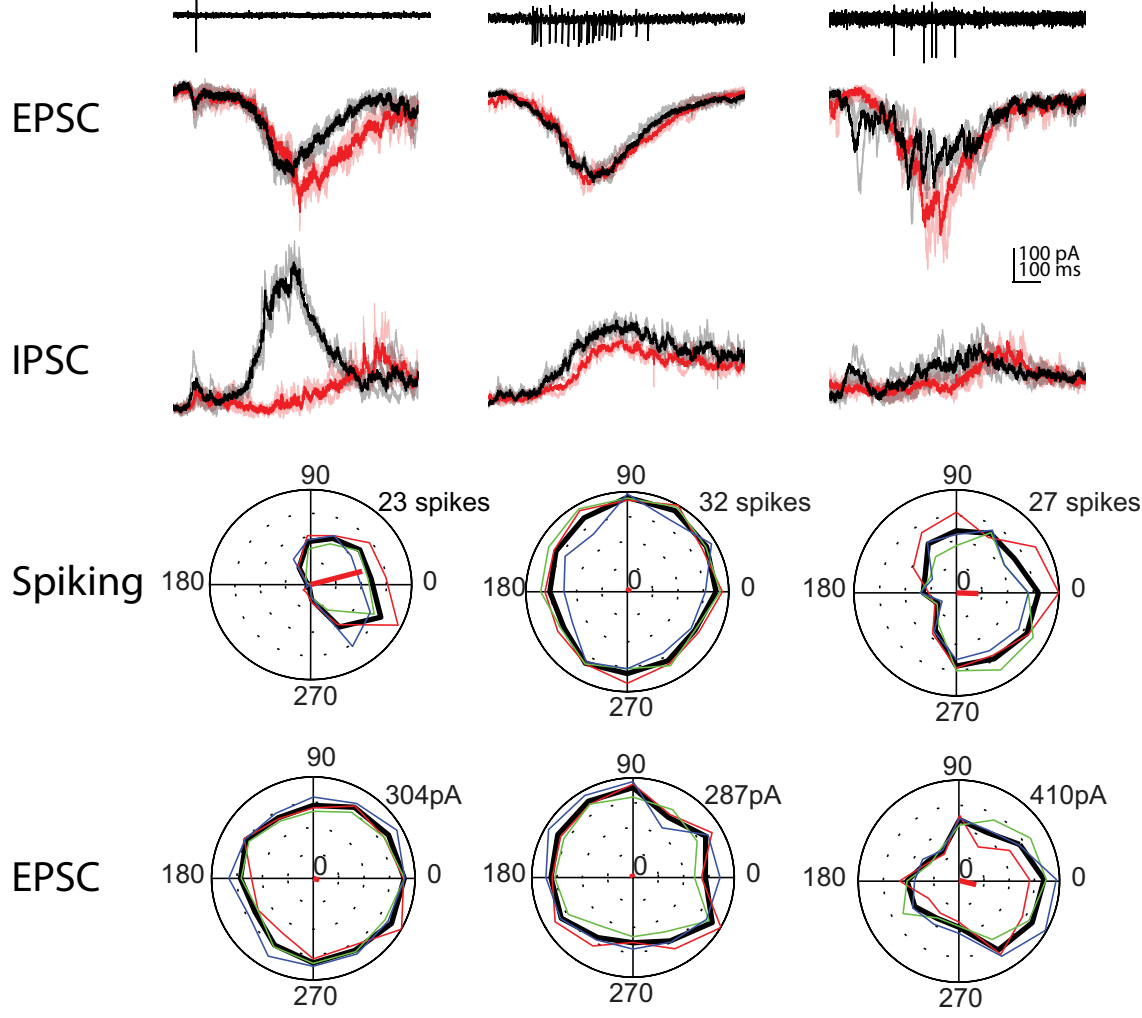

Figure 5. Different patterns of excitatory and inhibitory inputs underlie direction-selective spiking of pDSGCs. $\boldsymbol{A}$, Example cell from a control mouse showing its spiking activity and excitatory and inhibitory currents evoked by preferred (red) and null (black) direction motion. The preferred direction is determined from spiking activity. Top four rows: traces from electrophysiological recordings of spikes and excitatory (inward) and inhibitory (outward) currents. Lighter traces are three individual repetitions and dark traces are the mean traces of the three repetitions. Lower three rows: polar plots of spiking responses and peak amplitudes of EPSCs and IPSCs. The $0 n$ responses evoked by the leading edge of the moving bar are shown in this and subsequent examples in this figure. $\boldsymbol{B}$, Example cell from the non-DS group in a Vgat ${ }^{\text {flox/flox }}$ CTD mouse. Excitatory inputs onto this cell are not direction selective. The relative timing between excitation and inhibition is similar for the preferred and null direction motion. $C$, Example cell from the DS group that received direction-selective excitatory inputs and slightly delayed inhibitory inputs in the preferred direction motion. integrated in each bin for preferred and null directions (Fig. 7B). Cross-correlograms show that spiking activity is strongly correlated with the excitatory currents (Fig. 7C,D). We did not observe an improved correlation between spiking activity and $\Delta g$ (Fig. $7 C, D)$. This result lends further support to an important role of direction-selective excitation in direction-selective spiking in $V$ gat ${ }^{\text {flox/flox }}$ CTD mice.

\section{Cholinergic component is directional in the DS group of Vgat $^{\text {flox/flox }} C T D$ mice}

Because DSGCs receive glutamatergic and cholinergic inputs from bipolar cells and SACs, respectively, we investigated which 
A

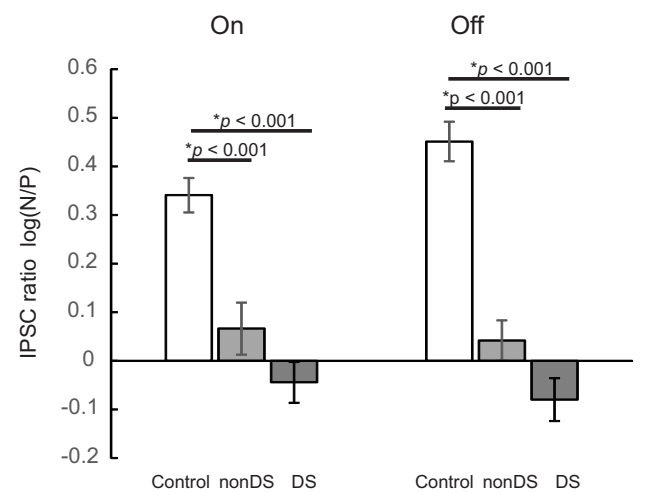

C

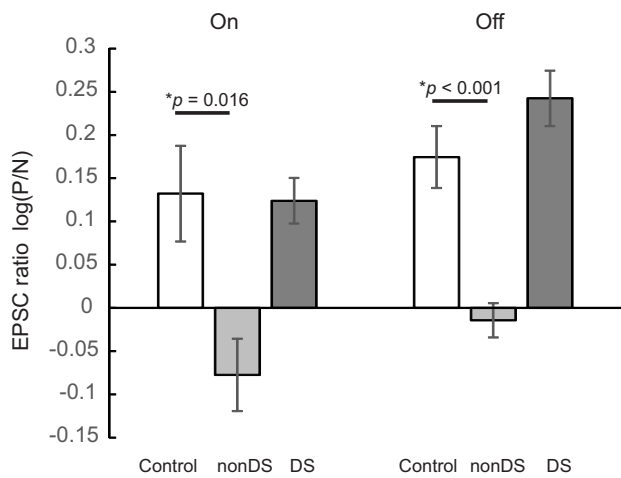

B

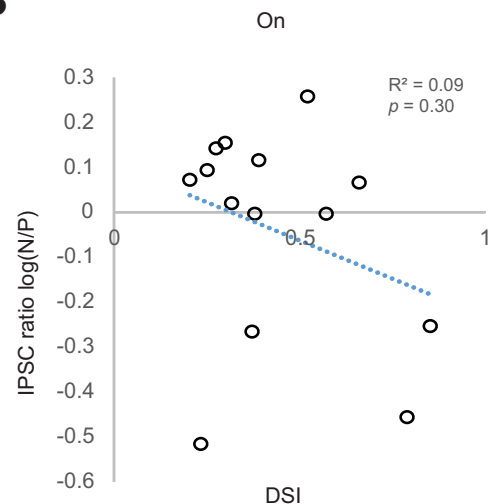

D

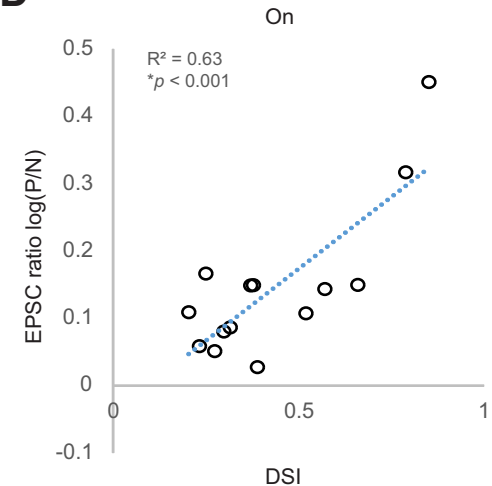

Off

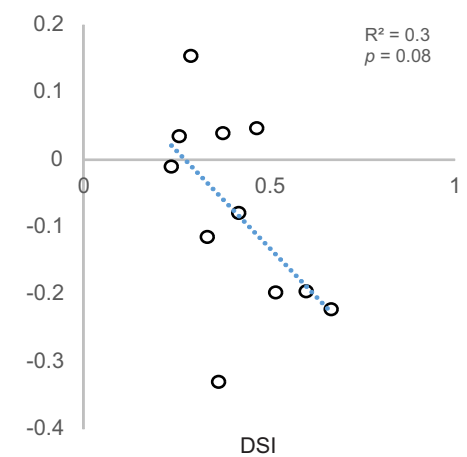

Off

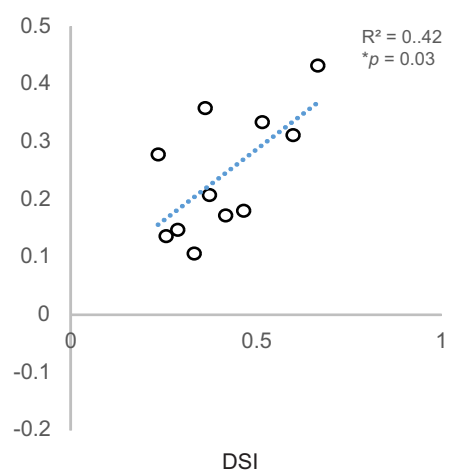

G
E

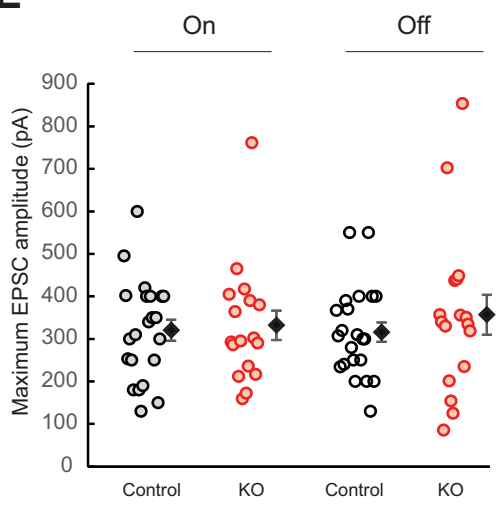

F

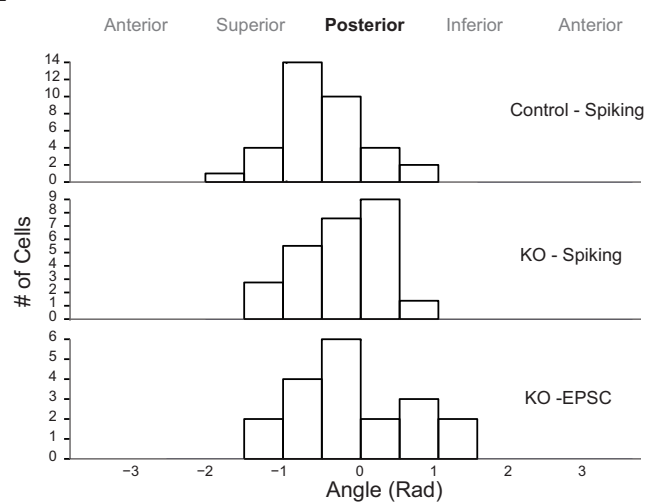

Control

KO-DS
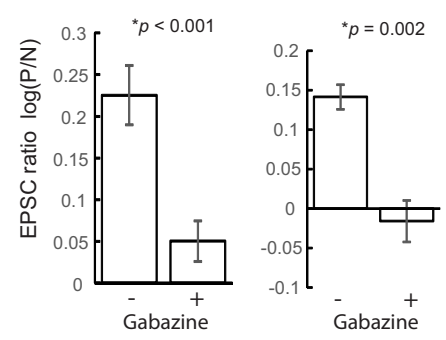

Figure 6. The excitatory but not inhibitory inputs onto the pDSGCS from the DS group in Vgat flox/flox $C T D$ mice are directionally tuned to the posterior direction. $A$, Summary plot showing the log ratio of IPSC amplitudes in the null and preferred directions ( $\log (\mathrm{N} / \mathrm{P})$ ) for $0 \mathrm{n}$ and Off components for control ( $n=17$ cells, 11 mice), non-DS (On: $n=6$ cells, off: $n=11$ cells), and DS (On: $n=14$ cells, Off: $n=11$ cells, $0 \mathrm{n}$ and Off data from 18 mice) groups. Data are represented as mean \pm SEM. On: Control $0.34 \pm 0.04$, non-DS 0.07 \pm 0.05 , DS $-0.04 \pm 0.04$; Off: Control 0.45 \pm 0.04 , non-DS $0.05 \pm 0.04$, DS $-0.08 \pm 0.04$. B, Scatter plots of IPSC $\log (\mathrm{N} / \mathrm{P}$ ) ratio versus spike DSI for On (left) and Off (right) components in the DS group. DSI values for On and Off spiking activity are calculated separately. Dashed lines indicate linear regression fit for this and subsequent plots. C, Summary plot showing the log ratio of EPSC amplitudes in the preferred and null directions [log(P/N)] for On and Off components for control ( $n=17$ cells, 11 mice), non-DS ( $0 \mathrm{n}: n=6$ cells, Off: $n=11$ cells), and DS ( $0 \mathrm{n}: n=14$ cells, Off: $n=11$ cells, On and Off data from 18 mice) groups. On: Control $0.13 \pm 0.06$, non-DS $-0.08 \pm 0.04$, DS $0.12 \pm 0.03$; Off: Control $0.17 \pm 0.04$, non-DS $-0.01 \pm 0.02, \mathrm{DS} 0.24 \pm 0.03$. D, Scatter plots of EPSCP/N ratio versus spike DSI for On (left) and Off (right) components in the DS group. E, Summary plot showing maximum EPSC amplitudes in pDSGCs from control and KO groups. Filled diamonds represent mean \pm SEM. On: (ontrol $320.5 \pm 25.0 \mathrm{pA}$, K0 332.1 \pm 34.4 pA; Off: Control $315.8 \pm 22.7$ pA, K0 $357.0 \pm 46.9$ pA. F, Histograms of preferred directions calculated from spiking activity in control mice (top) and spiking activity (middle) and EPSC amplitude (bottom) in KO mice. The preferred directions of EPSCs are determined from the vector sums of peak amplitudes from 12 directions. The visual coordinates are labeled on the top of the histograms. G, Summary plot showing the log of EPSCP/N ratio before (-) and after $(+)$ gabazine application in control and the DS group in Vgat ${ }^{\text {floxfflox }}$ (TD mice (KO-DS). Control mice: before gabazine, $0.23 \pm 0.04$; after gabazine, $0.05 \pm 0.02, n=20$ cells, 8 mice; KO-DS: before gabazine, $0.14 \pm 0.02$; after gabazine, $-0.02 \pm 0.02, n=8$ cells, 5 mice. On and 0ff components are pooled together.

component of the EPSCs is direction selective in $V$ gat ${ }^{\text {flox/flox }} C T D$ mice. We recorded moving bar-evoked EPSCs from cells in the DS group before and after applying the nicotinic receptor antagonist DH $\beta$ E (Fig. $8 A$ ). DH $\beta$ E has been shown to completely block the cholinergic inputs from SACs to DSGCs (Wei et al.,
2011). DH $\beta$ E-sensitive currents are obtained by subtracting the residual EPSC trace from the one before addition of $\mathrm{DH} \beta \mathrm{E}$. We found that $\mathrm{DH} \beta \mathrm{E}$ significantly reduced the peak $\mathrm{P} / \mathrm{N}$ ratios of EPSCs. However, the $\mathrm{DH} \beta \mathrm{E}$-sensitive currents are direction selective and tuned to the posterior direction in both the On (Fig. 
A
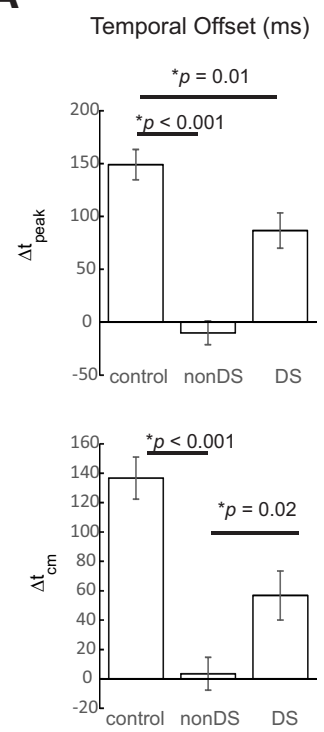

B
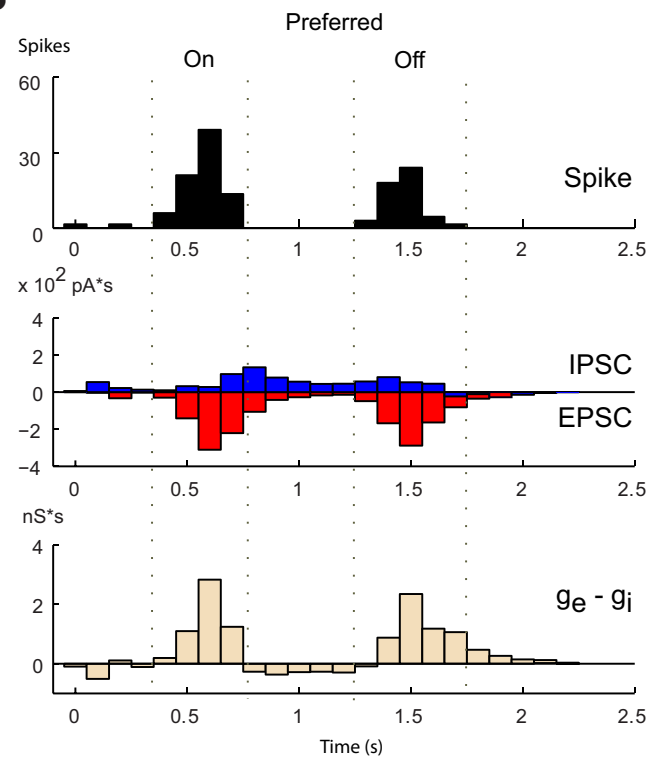

C

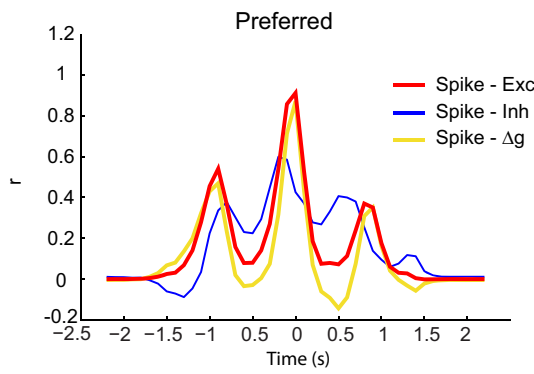

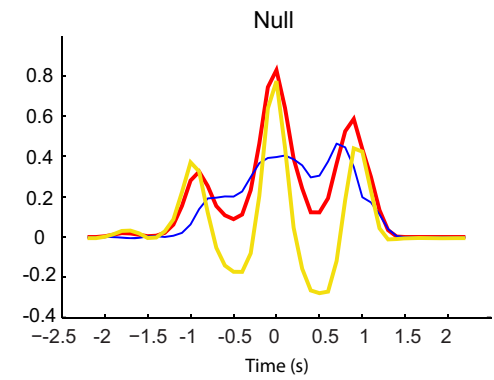
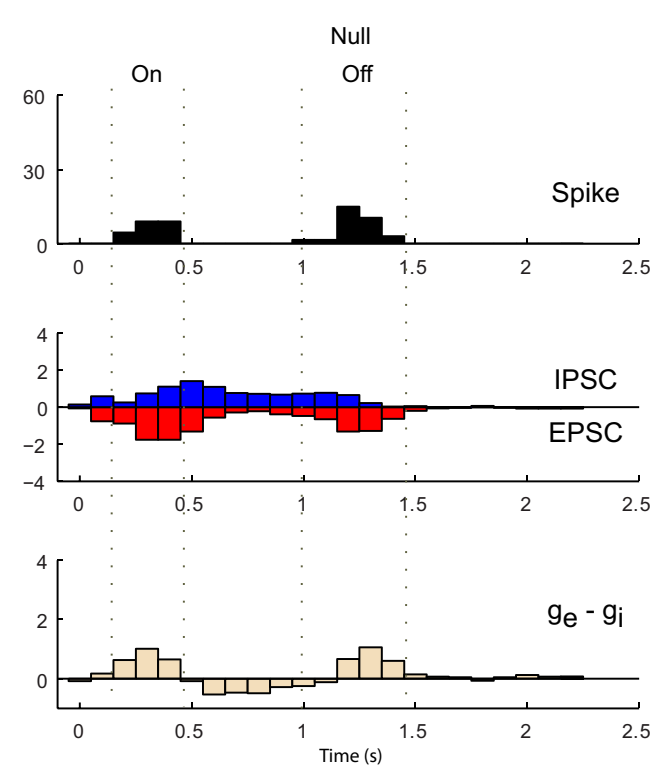

D

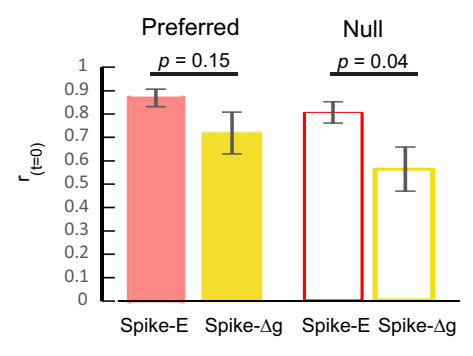

Figure 7. Relation between spiking activity and the time course of excitation and inhibition onto pDSGCs in Vgat ${ }^{\text {flox/flox }}$ CTD mice. $A$, Summary plots showing the temporal offset of $t_{\text {peak }}$ or $t_{\text {cm }}$ between EPSCs and IPSCs in pDSGCs evoked by the leading edge of a bright moving bar from the control, non-DS, and DS groups ( $\Delta t_{\text {peak }}$ : control, $149.0 \pm 14.35$ ms, $n=20$ cells; non-DS, $-10.0 \pm$ $11.2 \mathrm{~ms}, n=6$ cells; DS, $86.7 \pm 16.7 \mathrm{~ms}, n=14$ cells; $\Delta t_{\mathrm{cm}}$, control: $136.7 \pm 22.7 \mathrm{~ms}$; non-DS, $3.5 \pm 9.6 \mathrm{~ms}$; DS, $56.8 \pm 23.4 \mathrm{~ms} . \boldsymbol{B}$, Temporally aligned spike-density histograms (top), current-density histograms (middle) for EPSCs (red, inward) and IPSCs (blue, outward), and the relative difference between excitatory and inhibitory conductances ( $\Delta g$, bottom) of a pDSGC in preferred and null directions of a moving bar stimulus. For $\boldsymbol{B}$ and $\boldsymbol{C}, 100 \mathrm{~ms}$ bins are used. Time windows of $0 \mathrm{n}$ and 0 ff spikes are indicated by dashed lines. $\boldsymbol{C}$, $\boldsymbol{C}$ (ross-correlograms for the neuron in $\boldsymbol{B}$. The spiking activity, EPSC, and $\Delta g$ covary synchronously, as indicated by the correlation coefficient peaking at the $t=0$ bin. The two smaller peaks at both sides result from the cross-correlation between $0 \mathrm{n}$ and $0 \mathrm{ff}$ responses during the moving bar stimulus. $D$, Summary plots showing the cross-correlation coefficient at $t=0$ between spiking and EPSC and between spiking and $\Delta g$ in the preferred and null directions (preferred direction: spike vs EPSC, $0.87 \pm 0.04 ;$ spike vs $\Delta g, 0.72 \pm 0.09 ;$ null direction: spike vs EPSC, $0.80 \pm 0.04 ;$ spike vs $\Delta g, 0.56 \pm 0.09, n=8$ cells).

$8 B-D)$ and Off (Fig. $8 E, F)$ components. Therefore, directionally tuned excitation in $V g a t^{\text {flox/flox }}$ CTD mice is mostly attributed to cholinergic inputs from SACs.

\section{Direction selectivity of pDSGCs in $V g a t^{\text {flox/flox }} C T D$ mice is not due to asymmetric distribution of their dendritic arbors} Asymmetric distribution of dendritic arbors has been proposed as another mechanism underlying direction selectivity in a subtype of On-Off DSGCs that prefer motion in the superior direction (Kay et al., 2011; Trenholm et al., 2011) and in a class of Off DSGCs (Kim et al., 2008). To determine whether the direction selectivity observed in pDSGCs from $V g a t^{\text {flox/flox }} C T D$ mice results from asymmetric dendritic morphology, we compared the area (Fig. 9A) and the total length (Fig. 9C) of dendritic arbors occupying the preferred side versus those occupying the null side and calculated the $\mathrm{P} / \mathrm{N}$ ratios for each $\mathrm{pDSGC}$. We found random distribution of dendrites along the preferred-null axis and a lack of correlation between the $\mathrm{P} / \mathrm{N}$ ratio for dendritic arbor area or length and spike DSI (Fig. 9B,D). Therefore, dendritic morphology does not dictate the directional preference in the pDSGCs in Vgat ${ }^{\text {flox/flox }}$ CTD mice.

\section{Discussion}

This study shows that, in the absence of direction-selective inhibition, direction selectivity is not completely abolished in a subset of DSGCs, but is implemented by direction-selective excitatory inputs and temporally offset inhibition. Therefore, multiple synaptic mechanisms act synergistically to ensure robust direction selectivity of mouse DSGCs.

An indispensable role of SACs in direction selectivity has been supported by multiple studies that selectively ablated SACs by toxin treatment (Amthor et al., 2002; Yoshida et al., 2001) or chemogenetic silencing (Vlasits et al., 2014). Because these manipulations abolish both GABA and acetylcholine release from SACs, loss of direction selectivity observed in these studies can result from lack of both excitatory and inhibitory mechanisms. In this study, GABA, but not acetycholine release, was selectively blocked from SACs.

Pharmacological blockade of GABA receptors by antagonists has been shown to cause loss of direction-selective spiking activity in DSGCs (Caldwell et al., 1978; Ariel and Daw, 1982; Cohen and Miller, 1995; Kittila and Massey, 1995; Chiao and Masland, 
A

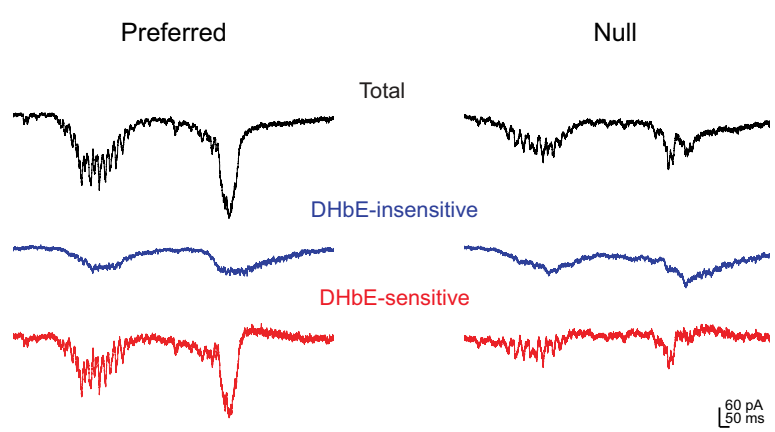

C

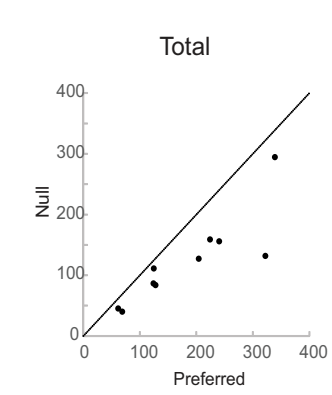

E

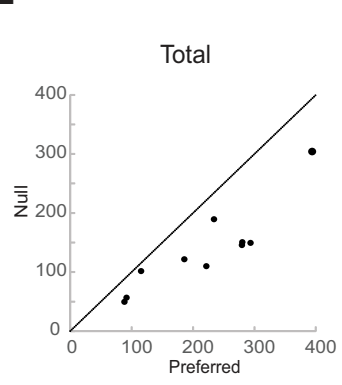

On

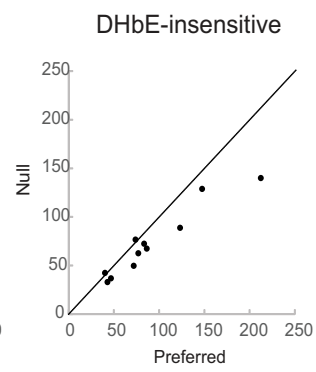

Off

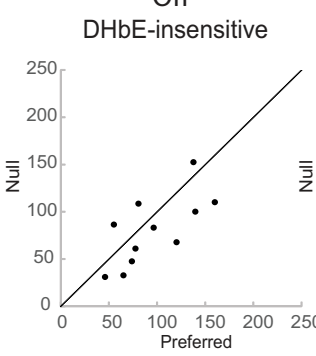

B
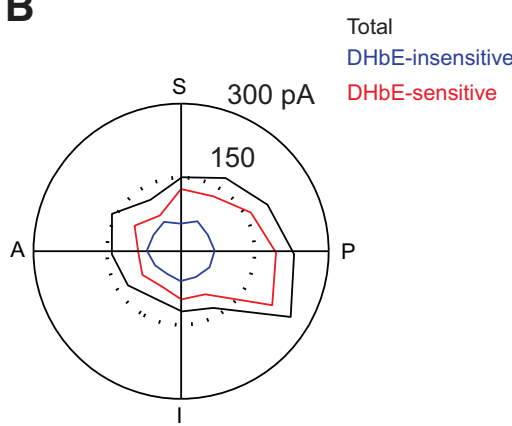

D

On

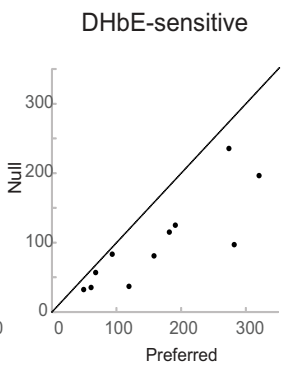

F
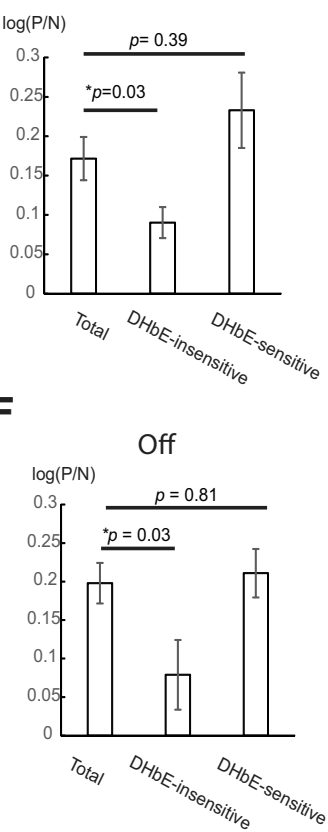

Figure 8. Cholinergic component of the EPSCs in the DS group from the V $g$ at ${ }^{\text {floxfflox }}$ CTD mice is direction selective. $A$, Mean EPSC traces (average over three trials) of a pDSGC in the DS group evoked by a moving bar in the preferred and null directions. EPSCs were recorded before (top) and after (middle) $0.08 \mu \mathrm{m} \mathrm{DH} \beta \mathrm{E}$ was applied through perfusion. The subtracted trace (bottom) represents the $\mathrm{DH} \beta \mathrm{E}$-sensitive cholinergic component of the EPSCS. B, Polar plot of the peak amplitude of the 0 responses for the total (black), DH $\beta$ E-insensitive glutamatergic (blue), and DH $\beta \mathrm{E}$-sensitive cholinergic (red) components from the cell in A.P, Posterior; A, anterior; S, superior; I, inferior. C, For On responses, scatter plots of EPSC peak amplitudes evoked by null-direction motion against those evoked by preferred-direction motion for the total (left), DH $\beta$ E-insensitive (middle), and DH $\beta$ E-sensitive (right) components. Diagonal lines are unity lines. $D$, Summary plot showing the log ratio of EPSC amplitudes in the preferred and null directions $[\log (\mathrm{P} / \mathrm{N})]$ for the $0 \mathrm{n}$ response for the total (left), DH $\beta \mathrm{E}$-insensitive (middle), and DH $\beta \mathrm{E}$-sensitive (right) components. Total: $0.17 \pm 0.03$; DH $\beta$ E-insensitive: $0.09 \pm 0.02$; DH $\beta$ E-sensitive: $0.23 \pm 0.05 ; n=11$ cells, 8 mice. $\boldsymbol{E}$, As in $\boldsymbol{C}$, scatter plots for 0ff responses. $\boldsymbol{F}$, As in $\boldsymbol{D}$, summary plot showing the log ratio of EPSC amplitudes in the preferred and null directions $[\log (\mathrm{P} / \mathrm{N})]$ for the $0 \mathrm{ff}$ response. Total: $0.20 \pm 0.03 ; \mathrm{DH} \beta \mathrm{E}$-insensitive: $0.08 \pm 0.05$; DH $\beta \mathrm{E}-$ sensitive: $0.21 \pm 0.03$.

2002; Weng et al., 2005). In addition to blocking GABAergic inhibition, GABA receptor antagonists also abolished directionselective excitatory inputs onto DSGCs in wild-type (Fried et al., 2005; Lee et al., 2010) and Vgat ${ }^{\text {flox/flox }} C T D$ (Fig. 6G) mice. Results from these pharmacological experiments can be interpreted in the following two ways. First, direction-selective excitation is generated by presynaptic inhibition onto excitatory presynaptic terminals. Because the residual GABAergic inputs from SACs to DSGCs in $V g a t{ }^{\text {flox/flox }} C T D$ mice are nondirectional, this directional presynaptic inhibition likely comes from additional GABAergic amacrine cell types other than SACs (Hoggarth et al., 2015; Park et al., 2015). The second interpretation is that the relatively small differences in EPSCs in the preferred and null directions may be masked by hyperactivity of retinal network when GABAergic inhibition is nonspecifically blocked by antagonists. We cannot distinguish between the above two possibilities. Furthermore, vGluT3-expressing amacrine cells (Lee et al.,
2014) have been shown recently to provide excitatory inputs onto DSGCs. How this and other recently identified amacrine cell types are involved in the direction-selective excitatory inputs described in this study is not clear and awaits future studies.

Deletion of Vgat from SACs by ChAT-IRES-Cre expression appears to cause no detectable change in the rest of the directionselective circuit during development. Both the SAC-DSGC cholinergic synapses and GABA receptor expression on pDSGCs appear to be unaffected. The strength of light-evoked EPSCs in $V g a t{ }^{\text {flox/flox }} C T D$ mice is comparable to that in the wild-type animals. Furthermore, we did not detect enhanced direction selectivity of excitatory inputs in the conditional knock-out mice, suggesting that there is little developmental compensation or reorganization of other synapse types when GABA release from SACs is impaired. Lack of heterosynaptic competition and lack of coregulation of excitation and inhibition have also been demonstrated in other retinal circuits in mice (Schubert et al., 2013; 
A
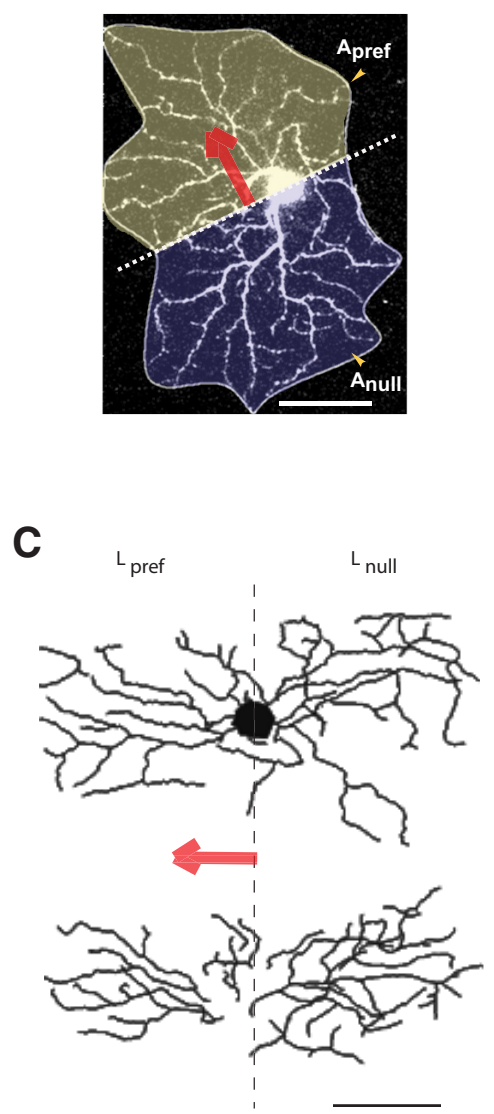

B

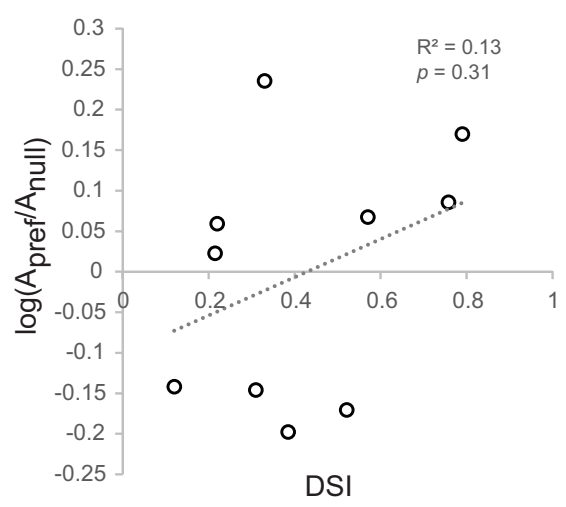

D

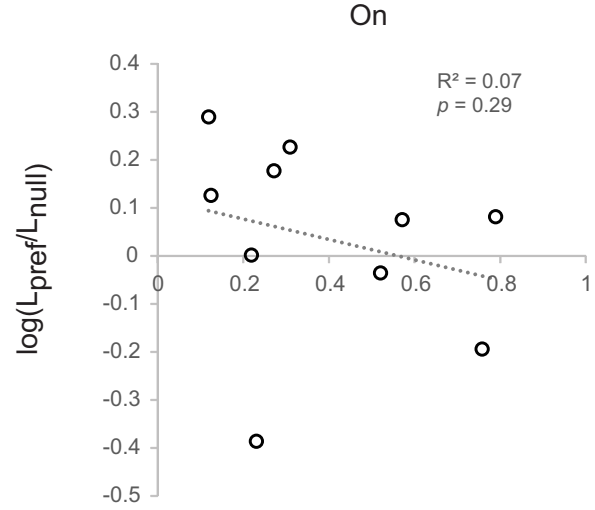

DSI
Off

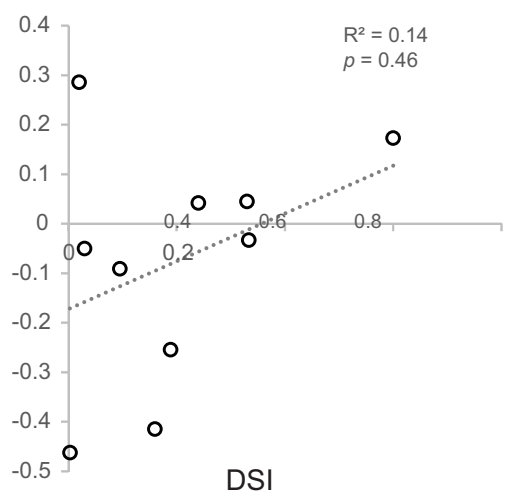

Off

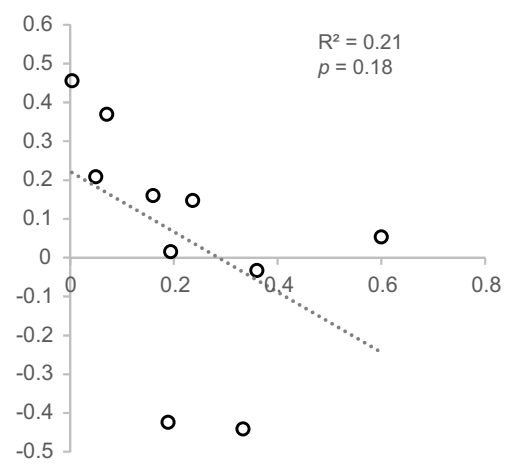

DSI

Figure 9. The orientation of dendritic arbors of pDSGCS in Vgat flox/flox CTD mice does not predict the cells' preferred directions. $A$, Schematic showing the method of measuring dendritic arbor area occupying the preferred $\left(A_{\text {pref }}\right)$ and null $\left(A_{\text {null }}\right)$ sides of a pDSGC in a Vgat ${ }^{\text {flox/flox }}$ CTD mouse. The image is the Z projection of the On layer of a pDSGC's dendrites acquired by two-photon imaging. Red arrow indicates preferred direction of the cell's spiking activity. Scale bar, $50 \mu \mathrm{m}$. B, Scatter plots of the log of the area ratio $A_{\text {pref }} / A_{\text {null }}$ versus spike DSI in Vgat flox/flox $C T D$ mice for the $0 \mathrm{n}$ and 0 Off components. $C$, Example of reconstructed On and Off dendritic arbors of a pDSGC for calculating dendritic length. Scale bars, $50 \mu \mathrm{m}$. $D$, Same as $B$, scatter plots of log dendritic length ratio $L_{\text {pref }} / L_{\text {null }}$ versus spike DSI in Vgat ${ }^{\text {floxfflox }}$ CTD mice.

Okawa et al., 2014). Therefore, the results from $V g a t{ }^{\text {flox/flox }} C T D$ mice likely reflect the contributions of excitatory mechanisms to direction selectivity in normal healthy mice, but we cannot completely exclude the possibility of compensatory changes in the circuit.

A major concern about direction-selective excitation observed in voltage-clamp experiments is the underestimation of EPSCs during motion in the null direction due to the presence of strong inhibitory inputs (Poleg-Polsky and Diamond, 2011; Vaney et al., 2012). In Vgat ${ }^{\text {flox/flox }} C T D$ mice, null-direction inhibition is severely reduced to a level similar to preferred-direction inhibition or, in some cases, is completely eliminated. This should substantially alleviate the distortion of EPSCs by IPSCs during null-direction motion. Direction-selective excitation is still present in the DS group under these conditions, indicating that there is a genuine difference in the strength of excitatory inputs onto those DSGCs during motion in the preferred and null directions. Furthermore, blocking the cholinergic component of excitation in the DS group reduced direction tuning of excitation, which cannot be explained by voltage-clamp artifacts. The existence of direction-selective excitation in $V g a t^{\text {flox/flox }} C T D$ mice also implies that direction-selective EPSCs of DSGCs measured in wild-type mice reflect a genuine excitatory input pattern, although this direction-selective excitation might be quantitatively overestimated because of space-clamp issues, especially at the Off dendritic arbors (Poleg-Polsky and Diamond, 2011). In contrast, pDSGCs in the non-DS group lack directional tuning of their excitation. It is possible that GABA release from SACs is critical for generating direction-selective excitation in the non-DS group. Alternatively, direction-selective excitation may not be a universal mechanism for all DSGCs. Either possibility highlights the heterogeneity of excitatory mechanisms in the directionselective circuit.

We found that directional excitation in $V g a t^{\text {flox/flox }} C T D$ mice is unlikely to be attributed to glutamatergic inputs onto DSGCs. This is consistent with results from functional imaging studies in wild-type mice, which used an extracellular glutamate sensor (iGluSnFR) expressed in On DSGCs and a subtype of On-Off DSGCs and a calcium sensor (GCaMP3) expressed in On bipolar cell terminals. These studies reported nondirectional glutamatergic responses from these sensors during motion stimuli (Yonehara et al., 2013; Chen et al., 2014; Park et al., 2014), indicating that the glutamatergic component of the excitatory conductances is not direction selective in wild-type mice.

The role of acetylcholine in direction selectivity has been less clear. During blockade of GABAergic inhibition, cholinergic excitation has been implicated in motion facilitation in all directions (He and Masland, 1997; Chiao and Masland, 2002). 
However, whether the contribution of cholinergic excitation is directional in the absence of GABA antagonists has been controversial. Several extracellular recording studies using moving bars showed that nicotinic antagonists do not abolish direction selectivity (Ariel and Daw, 1982; Cohen and Miller, 1995; Kittila and Massey, 1995). In contrast, other studies using drifting gratings showed that a nicotinic antagonist largely eliminated direction selectivity (Grzywacz et al., 1998a, 1998b). Furthermore, in whole-cell recordings, direction-selective modulation of cholinergic inputs onto DSGCs has been reported (Fried et al., 2005; Lee et al., 2010; but see Park et al., 2014). In this study, we also observe direction-selective cholinergic excitation, suggesting that this mechanism may be used by both wild-type and $V$ gat ${ }^{\text {flox/flox }} C T D$ mice. The conflicting results from past studies may be explained by variability in experimental conditions. Indeed, light responses of retinal ganglion cells have been shown to change with background luminance and contrast (Tikidji-Hamburyan et al., 2015; Pearson and Kerschensteiner, 2015) and the mechanisms of direction selectivity may be modulated by visual stimulus conditions (Vlasits et al., 2014; Lipin et al., 2015).

It is noteworthy that SAC-mediated GABA release in $V g a t{ }^{\text {flox/flox }} C T D$ mice is not completely abolished, consistent with previous studies on VGAT knock-out mouse lines (Wojcik et al., 2006; Tritsch et al., 2012). The residual light-evoked IPSCs may come from the residual GABAergic transmission from SACs shown in paired recordings or from inhibitory inputs from other amacrine cell types (Hoggarth et al., 2015; Park et al., 2015). For the pDSGCs in the DS group, although the inhibitory inputs are nondirectional, the temporal offset is present albeit reduced compared with the wild-type. This residual temporal offset might result from the weak, statistically nonsignificant bias of residual inhibitory inputs coming from the null-side SACs (Fig. 1D, KO pref vs $\mathrm{KO}$ null). Because SAC processes prefer motion in the centrifugal direction in the wild-type animal, it is unclear why slightly more inputs from null-side SACs did not produce slightly stronger residual inhibition during null-direction motion. One possibility is that reducing GABA release from SACs impairs the centrifugal preference in SACs due to disrupted reciprocal inhibition among SACs (Lee and Zhou, 2006; Münch and Werblin, 2006; but see Euler et al., 2002; Hausselt et al., 2007; Oesch and Taylor, 2010). Another possibility is that SAC processes are still depolarized more strongly by centrifugal motion, but depletion of vesicular GABA in Vgat knock-out mice has a more severe impact on GABA release during the more strongly depolarizing centrifugal stimuli, resulting in overall nondirectional GABA release from SAC processes.

The spiking pattern of DSGCs depends on the interaction between the intrinsic properties of dendrites and patterned excitatory and inhibitory inputs (Oesch et al., 2005; Cafaro and Rieke, 2010; Schachter et al., 2010; Sivyer and Williams, 2013; Trenholm et al., 2014). In wild-type mice, motion in the null direction evokes powerful inhibitory inputs onto DSGCs that occur simultaneously with excitatory inputs, whereas motion in the preferred direction evokes weak inhibitory inputs that are significantly delayed compared with the excitatory inputs. These factors contribute synergistically to the selective suppression of null-direction spiking. In Vgat ${ }^{\text {flox/flox }} C T D$ mice, the inhibition in the null direction is severely weakened (similar to the level of that in the preferred direction) and therefore is less effective in vetoing the spiking activity driven by excitatory inputs. As a result, spike generation is strongly correlated with EPSCs in $V$ gat ${ }^{\text {flox/flox }}$ CTD mice. In addition, both spiking activity and EPSCs are tuned to the posterior direction. Together, these findings highlight the importance of an excitation-inhibition interaction in sensory processing and strongly support a role of directional excitation in direction selectivity in a subpopulation of DSGCs.

\section{References}

Agmon-Snir H, Segev I (1993) Signal delay and input synchronization in passive dendritic structures. J Neurophysiol 70:2066-2085. Medline

Amthor FR, Keyser KT, Dmitrieva NA (2002) Effects of the destruction of starburst-cholinergic amacrine cells by the toxin AF64A on rabbit retinal directional selectivity. Vis Neurosci 19:495-509. Medline

Ariel M, Daw NW (1982) Pharmacological analysis of directionally sensitive rabbit retinal ganglion cells. J Physiol 324:161-185. CrossRef Medline

Barlow HB, Hill RM (1963) Selective sensitivity to direction of movement in ganglion cells of the rabbit retina. Science 139:412-414. CrossRef Medline

Berson DM (2008) Retinal ganglion cell types and their central projections. In: The senses: a comprehensive reference, Vol 1, Vision (Albright TD, Masland R, eds), pp 491-520. San Diego: Academic.

Brecha N, Johnson D, Peichl L, Wässle H (1988) Cholinergic amacrine cells of the rabbit retina contain glutamate decarboxylase and gammaaminobutyrate immunoreactivity. Proc Natl Acad Sci U S A 85:61876191. CrossRef Medline

Briggman KL, Helmstaedter M, Denk W (2011) Wiring specificity in the direction-selectivity circuit of the retina. Nature 471:183-188. CrossRef Medline

Cafaro J, Rieke F (2010) Noise correlations improve response fidelity and stimulus encoding. Nature 468:964-967. CrossRef Medline

Caldwell JH, Daw NW, Wyatt HJ (1978) Effects of picrotoxin and strychnine on rabbit retinal ganglion cells: lateral interactions for cells with more complex receptive fields. J Physiol 276:277-298. CrossRef Medline

Chen M, Lee S, Park SJ, Looger LL, Zhou ZJ (2014) Receptive field properties of bipolar cell axon terminals in direction-selective sublaminas of the mouse retina. J Neurophysiol 112:1950-1962. CrossRef Medline

Chiao CC, Masland RH (2002) Starburst cells nondirectionally facilitate the responses of direction-selective retinal ganglion cells. J Neurosci 22: 10509-10513. Medline

Cohen ED, Miller RF (1995) Quinoxalines block the mechanism of directional selectivity in ganglion cells of the rabbit retina. Proc Natl Acad Sci U S A 92:1127-1131. CrossRef Medline

Efron B, Tibshirani RJ (1994) An introduction to the bootstrap. San Diego: CRC.

Euler T, Detwiler PB, Denk W (2002) Directionally selective calcium signals in dendrites of starburst amacrine cells. Nature 418:845-852. CrossRef Medline

Fried SI, Münch TA, Werblin FS (2002) Mechanisms and circuitry underlying directional selectivity in the retina. Nature 420:411-414. CrossRef Medline

Fried SI, Münch TA, Werblin FS (2005) Directional selectivity is formed at multiple levels by laterally offset inhibition in the rabbit retina. Neuron 46:117-127. CrossRef Medline

Grzywacz NM, Amthor FR, Merwine DK (1998a) Necessity of acetylcholine for retinal directionally selective responses to drifting gratings in rabbit. J Physiol 512:575-581. CrossRef Medline

Grzywacz NM, Merwine DK, Amthor FR (1998b) Complementary roles of two excitatory pathways in retinal directional selectivity. Vis Neurosci 15:1119-1127. Medline

Hausselt SE, Euler T, Detwiler PB, Denk W (2007) A dendrite-autonomous mechanism for direction selectivity in retinal starburst amacrine cells. PLoS Biol 5:e185. CrossRef Medline

He S, Masland RH (1997) Retinal direction selectivity after targeted laser ablation of starburst amacrine cells. Nature 389:378-382. CrossRef Medline

Hoggarth A, McLaughlin AJ, Ronellenfitch K, Trenholm S, Vasandani R, Sethuramanujam S, Schwab D, Briggman KL, Awatramani GB (2015) Specific wiring of distinct amacrine cells in the directionally selective retinal circuit permits independent coding of direction and size. Neuron 86:276-291. CrossRef Medline

Huberman AD, Wei W, Elstrott J, Stafford BK, Feller MB, Barres BA (2009) Genetic identification of an On-Off direction-selective retinal ganglion cell subtype reveals a layer-specific subcortical map of posterior motion. Neuron 62:327-334. CrossRef Medline

Kay JN, De la Huerta I, Kim IJ, Zhang Y, Yamagata M, Chu MW, Meister M, 
Sanes JR (2011) Retinal ganglion cells with distinct directional preferences differ in molecular identity, structure, and central projections. J Neurosci 31:7753-7762. CrossRef Medline

Kim IJ, Zhang Y, Yamagata M, Meister M, Sanes JR (2008) Molecular identification of a retinal cell type that responds to upward motion. Nature 452:478-482. CrossRef Medline

Kittila CA, Massey SC (1995) Effect of ON pathway blockade on directional selectivity in the rabbit retina. J Neurophysiol 73:703-712. Medline

Kosaka T, Tauchi M, Dahl JL (1988) Cholinergic neurons containing GABA-like and/or glutamic acid decarboxylase-like immunoreactivities in various brain regions of the rat. Exp Brain Res 70:605-617. Medline

Lee S, Zhou ZJ (2006) The synaptic mechanism of direction selectivity in distal processes of starburst amacrine cells. Neuron 51:787-799. CrossRef Medline

Lee S, Kim K, Zhou ZJ (2010) Role of ACh-GABA cotransmission in detecting image motion and motion direction. Neuron 68:1159-1172. CrossRef Medline

Lee S, Chen L, Chen M, Ye M, Seal RP, Zhou ZJ (2014) An unconventional glutamatergic circuit in the retina formed by vGluT3 amacrine cells. Neuron 84:708-715. CrossRef Medline

Lipin MY, Taylor WR, Smith RG (2015) Inhibitory input to the direction selective ganglion cells is saturated at low contrast. J Neurophysiol 114: 927-941. CrossRef Medline

Münch TA, Werblin FS (2006) Symmetric interactions within a homogeneous starburst cell network can lead to robust asymmetries in dendrites of starburst amacrine cells. J Neurophysiol 96:471-477. CrossRef Medline

Oesch NW, Taylor WR (2010) Tetrodotoxin-resistant sodium channels contribute to directional responses in starburst amacrine cells. PLoS One 5:e12447. CrossRef Medline

Oesch N, Euler T, Taylor WR (2005) Direction-selective dendritic action potentials in rabbit retina. Neuron 47:739-750. CrossRef Medline

Okawa H, Della Santina L, Schwartz GW, Rieke F, Wong RO (2014) Interplay of cell-autonomous and nonautonomous mechanisms tailors synaptic connectivity of converging axons in vivo. Neuron 82:125-137. CrossRef Medline

O'Malley DM, Masland RH (1989) Co-release of acetylcholine and gammaaminobutyric acid by a retinal neuron. Proc Natl Acad Sci U S A 86:34143418. CrossRef Medline

Oyster CW, Barlow HB (1967) Direction-selective units in rabbit retina: distribution of preferred directions. Science 155:841-842. CrossRef Medline

Park SJ, Kim IJ, Looger LL, Demb JB, Borghuis BG (2014) Excitatory synaptic inputs to mouse on-off direction-selective retinal ganglion cells lack direction tuning. J Neurosci 34:3976-3981. CrossRef Medline

Park SJ, Borghuis BG, Rahmani P, Zeng Q, Kim IJ, Demb JB (2015) Function and circuitry of VIP+ interneurons in the mouse retina. J Neurosci 35:10685-10700. CrossRef Medline

Pearson JT, Kerschensteiner D (2015) Ambient illumination switches contrast preference of specific retinal processing streams. J Neurophysiol 114:540-550. CrossRef Medline

Poleg-Polsky A, Diamond JS (2011) Imperfect space clamp permits electrotonic interactions between inhibitory and excitatory synaptic conductances, distorting voltage clamp recordings. PLoS One 6:e19463. CrossRef Medline

Schachter MJ, Oesch N, Smith RG, Taylor WR (2010) Dendritic spikes amplify the synaptic signal to enhance detection of motion in a simulation of the direction-selective ganglion cell. PLoS Comput Biol 6:pii:e1000899. CrossRef Medline

Schubert T, Hoon M, Euler T, Lukasiewicz PD, Wong RO (2013) Developmental regulation and activity-dependent maintenance of GABAergic presynaptic inhibition onto rod bipolar cell axonal terminals. Neuron 78:124-137. CrossRef Medline

Sivyer B, Williams SR (2013) Direction selectivity is computed by active dendritic integration in retinal ganglion cells. Nat Neurosci 16:18481856. CrossRef Medline

Stark E, Abeles M (2005) Applying resampling methods to neurophysiological data. J Neurosci Methods 145:133-144. CrossRef Medline

Taylor WR, Vaney DI (2002) Diverse synaptic mechanisms generate direction selectivity in the rabbit retina. J Neurosci 22:7712-7720. Medline

Tikidji-Hamburyan A, Reinhard K, Seitter H, Hovhannisyan A, Procyk CA, Allen AE, Schenk M, Lucas RJ, Münch TA (2015) Retinal output changes qualitatively with every change in ambient illuminance. Nat Neurosci 18:66-74. CrossRef Medline

Trenholm S, Johnson K, Li X, Smith RG, Awatramani GB (2011) Parallel mechanisms encode direction in the retina. Neuron 71:683-694. CrossRef Medline

Trenholm S, McLaughlin AJ, Schwab DJ, Turner MH, Smith RG, Rieke F, Awatramani GB (2014) Nonlinear dendritic integration of electrical and chemical synaptic inputs drives fine-scale correlations. Nat Neurosci 17: 1759-1766. CrossRef Medline

Tritsch NX, Ding JB, Sabatini BL (2012) Dopaminergic neurons inhibit striatal output through non-canonical release of GABA. Nature 490:262-266. CrossRef Medline

Vaney DI, Young HM (1988) GABA-like immunoreactivity in cholinergic amacrine cells of the rabbit retina. Brain Res 438:369-373. CrossRef Medline

Vaney DI, Sivyer B, Taylor WR (2012) Direction selectivity in the retina: symmetry and asymmetry in structure and function. Nat Rev Neurosci 13:194-208. Medline

Vlasits AL, Bos R, Morrie RD, Fortuny C, Flannery JG, Feller MB, Rivlin-Etzion M (2014) Visual stimulation switches the polarity of excitatory input to starburst amacrine cells. Neuron 83:1172-1184. CrossRef Medline

Wei W, Elstrott J, Feller MB (2010) Two-photon targeted recording of GFPexpressing neurons for light responses and live-cell imaging in the mouse retina. Nat Protoc 5:1347-1352. CrossRef Medline

Wei W, Hamby AM, Zhou K, Feller MB (2011) Development of asymmetric inhibition underlying direction selectivity in the retina. Nature 469:402406. CrossRef Medline

Weng S, Sun W, He S (2005) Identification of ON-OFF direction-selective ganglion cells in the mouse retina. J Physiol 562:915-923. CrossRef Medline

Wojcik SM, Katsurabayashi S, Guillemin I, Friauf E, Rosenmund C, Brose N, Rhee JS (2006) A shared vesicular carrier allows synaptic corelease of GABA and glycine. Neuron 50:575-587. CrossRef Medline

Yonehara K, Balint K, Noda M, Nagel G, Bamberg E, Roska B (2011) Spatially asymmetric reorganization of inhibition establishes a motionsensitive circuit. Nature 469:407-410. CrossRef Medline

Yonehara K, Farrow K, Ghanem A, Hillier D, Balint K, Teixeira M, Jüttner J, Noda M, Neve RL, Conzelmann KK, Roska B (2013) The first stage of cardinal direction selectivity is localized to the dendrites of retinal ganglion cells. Neuron 79:1078-1085. CrossRef Medline

Yoshida K, Watanabe D, Ishikane H, Tachibana M, Pastan I, Nakanishi S (2001) A key role of starburst amacrine cells in originating retinal directional selectivity and optokinetic eye movement. Neuron 30:771-780. CrossRef Medline 